\title{
PERSISTENCIAS Y RUPTURAS ESPACIALES EN EL ÁREA METROPOLITANA DE CÓRDOBA, ARGENTINA Descomposición gráfica - conceptual de la forma urbana del período 1980 - 2016
}

\author{
Claudia Marani \\ Facultad de Arquitectura, Urbanismo y Diseño. Universidad Nacional de Córdoba \\ Director: Dr. Arq. Fernando Díaz. Co-Directora: Dra. Arqta. Mariana Debat \\ claumarani.arq@gmail.com
}

\section{RESUMEN}

El modelo de ciudad- territorio de la dispersión demanda para su abordaje una aproximación transescalar. La lectura a través de los Sistemas Urbanos Territoriales y los Patrones de Asentamiento facilita arribar a la complejidad del AMC por medio de síntesis interpretativas, que al ser superpuestas posibilitan visualizar la integridad de las operaciones territoriales del periodo 1980-2016. Esto permite identificar cómo los temas emergentes se manifiestan en nuestro contexto impulsados o mitigados por las circunstancias propias del espacio metropolitano cordobés que, derivados de lógicas arraigadas a procesos temporales, determinan las formas de desarrollo urbano imperantes y las tendencias de crecimiento. La representación grafica manual se considera indispensable en la comprensión, apropiación, interpretación y construcción de nuevo conocimiento, como así también en la transmisión del mismo. La reformulación del área desde esta perspectiva podría promover lineamientos de proyecto más integrales, sensibles y responsables con el medio.

Palabras clave: patrones de asentamiento- sistemas urbanos territoriales- modelo- tendencial-

\begin{abstract}
The city-territory model of dispersion demands a trans-scalar approach for its approach. Reading through the Territorial Urban Systems and Settlement Patterns makes it easy to arrive at the complexity of the AMC by means of interpretive syntheses that, when overlapped, make it possible to visualize the integrity of the territorial operations of the period 1980-201. This allows us to identify how the emergent themes are manifested in our context driven or mitigated by the circumstances of the metropolitan space of Cordoba that, derived from logics rooted in temporal processes, determine the forms of prevailing urban development and trends of growth. Manual graphic representation is considered indispensable in the understanding, appropriation, interpretation and construction of new knowledge, as well as in the transmission of the same. The reformulation of the area from this perspective could promote more comprehensive, sensitive and responsible project guidelines with the environment.
\end{abstract}

Key words: Settlement patterns - Territorial urban systems -model - trend - 


\section{INTRODUCCIÓN}

La transición en el proceso de urbanización se manifiesta a través de nuevas formas territoriales, inestables, dada la velocidad de las transformaciones (Cicolella, Mignaqui, 2009). Las motivaciones de dicho proceso se corresponden a fenómenos de escala global, con los matices propios de las culturas locales. Al respecto, "debe considerarse las nuevas pautas de percepción y valoración del espacio que la sociedad ha ido construyendo en sus imaginarios, como producto de la alteración del modelo político - ideológico, de los instrumentos de gestión territorial y de las prácticas sociales y culturales" (Cicolella, 2003). El modelo de ciudad - región imperante, "difusa" (Dematteis, 1998), "sin confines" (Nello, 1998), demanda una mirada que trascienda lo sectorial en el abordaje de la "fragmentación como principio de estructuración espacial propio de las ciudades latinoamericanas en su fase más reciente de desarrollo urbano en América Latina" (Borsdorf, 2003).

En el contexto local, lo anteriormente descripto se evidencia en un AMC producto de dinámicas aparentemente contradictorias "resultado de procesos de crecimiento y transformación signados por la improvisación y la ausencia de planes, quedando los procesos librados a los impulsos del mercado" (IPLAM, 2008;15). Si bien la ciudad de Córdoba se consolida en materia legislativa en las décadas del ' 80 y '90 a través de un cuerpo normativo que regula el uso, ocupación y fraccionamiento del suelo, pierde vigencia y efectividad en el abordaje de los fenómenos urbanos contemporáneos que trascienden sus límites jurídicos. La expansión de la ciudad se torna incontenible dando lugar a un modelo fragmentado que invade el territorio a través de una gran cantidad de urbanizaciones monofuncionales y dependientes, que atentan las cualidades naturales, económicas y sociales de la región. Tal situación expone un escenario difícil y complejo que supera el cuerpo normativo y a los organismos de planificación existentes para conducir los procesos de transformación.

Las formas de crecimiento urbano vigentes y sus problemáticas y la falta de competencia de los municipios para resolver situaciones fuera de sus ejidos, hace cada vez más evidente la necesidad de acciones coordinadas a través de una visualización territorial. Cabe destacar la ausencia de cartografía soporte a tal fin. ${ }^{1}$ Por tal motivo, la investigación marco de la cual deriva el presente artículo aborda el AMC, en primera instancia, a través de la representación gráfica de los Sistemas Urbanos Territoriales (SUT). La técnica del dibujo manual se considera un recurso indispensable en la comprensión y apropiación de las escalas territoriales (Corboz 2003) y una herramienta de construcción de nuevo conocimiento (Sabate 2003). La deconstrucción del territorio en diversos momentos históricos a modo de capas temporales y la aproximación a cada una de ellas por medio de los SUT establecidos conforman la metodología que guía el presente estudio. Para su definición, se toma como referencia las nociones de Folch (2003) "sistema es el conjunto de elementos materiales de tal modo interrelacionados entre sí y/o interdependientes que constituyen un todo orgánico, inexplicable por la mera yuxtaposición de sus partes" y de Díaz (2014) que los define como configuraciones territoriales que se caracterizan por su condición de espacios con competencias compartidas, que constituyen la expresión de la complejidad supramunicipal y de la diversidad de manifestaciones espaciales; como estructuras urbanas en relación que pueden encauzar gestiones de cooperación interna, puesto que involucran intereses de diversas administraciones. En base a lo anteriormente expuesto, se aborda el AMC a través de estudio del sistema urbano territorial de las urbanizaciones identificando sus patrones y poniéndolo en relación con los sistemas de espacios abiertos ${ }^{2}$ y de movilidad ${ }^{3}$.

El método racional de comprender a la urbanización a través de los patrones de asentamiento o formas de crecimiento implica la consideración del tiempo como materia compositiva, donde la ciudad es producida en un momento dado, a través de formas de urbanización, parcelación y edificación, que en sus diferentes combinaciones, y según razonamientos propios de su lógica y condicionantes social e históricos, dan lugar a las formas urbanas (Sola-Morales, 1997). Localmente, Foglia (1987) desarrolla el concepto como formas de ocupación del medio natural a través de la urbanización y su configuración resultante, en un momento y sociedad determinada. Tomando de referencia de estos autores, se pretende determinar las configuraciones del AMC del periodo dilucidando usos de suelo dominantes y complementarios, morfologías resultantes y lógicas de expansión que les son propias.

\footnotetext{
${ }^{1}$ Las cartas de la República Argentina del Instituto Geográfico Militar (IGM) del Ejercito Nacional constituyen las últimas cartografías de registro del territorio que datan de la década del ' 70.

${ }^{2}$ constituido por cuencas, corredores hídricos, reservas naturales, áreas no urbanizables, zonas agrícolas- ganaderas, plazas y parques urbanos.

${ }^{3}$ integrado por redes, predios y estaciones ferroviarias y corredores viales, principalmente autopistas, rutas y caminos secundarios.
} 


\title{
2. EL ÁREA METROPOLITANA DE CÓRDOBA, ARGENTINA (AMC). LÍMITES Y CONCEPTUALIZACIÓN
}

Se utiliza los términos de Gran Córdoba, Región o Área Metropolitana para hacer referencia al conjunto de más de cuarenta municipios y comunas con Córdoba capital como ciudad dominante. La definición toma de referencia el concepto de Metrópolis entendido como una ciudad madre que ejerce significativa gravitación sobre otras menores. La población de esta área, perteneciente a la región central de la Argentina, se estima en 1.535.868 habitantes según el Instituto Nacional de Estadísticas y Censos (INDEC, 2010) y su superficie urbanizada se extiende siguiendo, principalmente, la dinámica de los corredores de movilidad radiales (Gráfico 1).

\section{CLASIFICACIÓN DE LOS PATRONES DE ASENTAMIENTO DEL AMC. PERIODO 1980 - 2016}

La siguiente categorización tiene por objeto detectar las formas urbanas del presente corte temporal, distinguiéndolas según sus características físicas e identificando las causas de crecimiento y las diferencias con las que se producen según sus propias lógicas. Se propone arribar a modo de primera aproximación y dado su mayor grado de impacto y predominio en el área de estudio con:

\author{
. Urbanizaciones cerradas. \\ Asentamientos informales. \\ . Políticas Habitacionales Públicas. \\ Cooperativas de Vivienda. \\ . Industria. \\ . Nodos comerciales y de entretenimiento.
}

\subsection{Urbanizaciones cerradas (UC)}

a) Suburbanas (UCS). Se toma de referencia la definición de barrios cerrados entendidos como "urbanizaciones de dos o más departamentos o casas que cuenta con una infraestructura común y se encuentran cercadas por muros o verjas, separados del espacio público mediante una barrera o puerta y vigilados por guardias o cámaras de video. A nivel de infraestructuras pueden incluir áreas verdes, equipamientos deportivos, áreas infantiles, piscina, y club house" (Borsdorf, 2003).

Localmente, este patrón se caracteriza por tener al uso de suelo residencial de sectores con poder adquisitivo medio -alto como dominante y por usos de suelo complementarios, entre los más frecuentes, el recreativo - deportivo (juegos infantiles, canchas de diversos deportes y piscinas cubiertas, sólo accesibles para residentes o personas afines autorizadas). En los últimos emprendimientos se considera la incorporación del suelo comercial en pequeñas fracciones y se evidencia la creciente exigencia del residente sobre los espacios abiertos y recreativos a través de propuestas que llegan a incluir, por ejemplo, entornos con lagunas artificiales (Aquavista Villa Residencial - Artemisa. Malagueño).

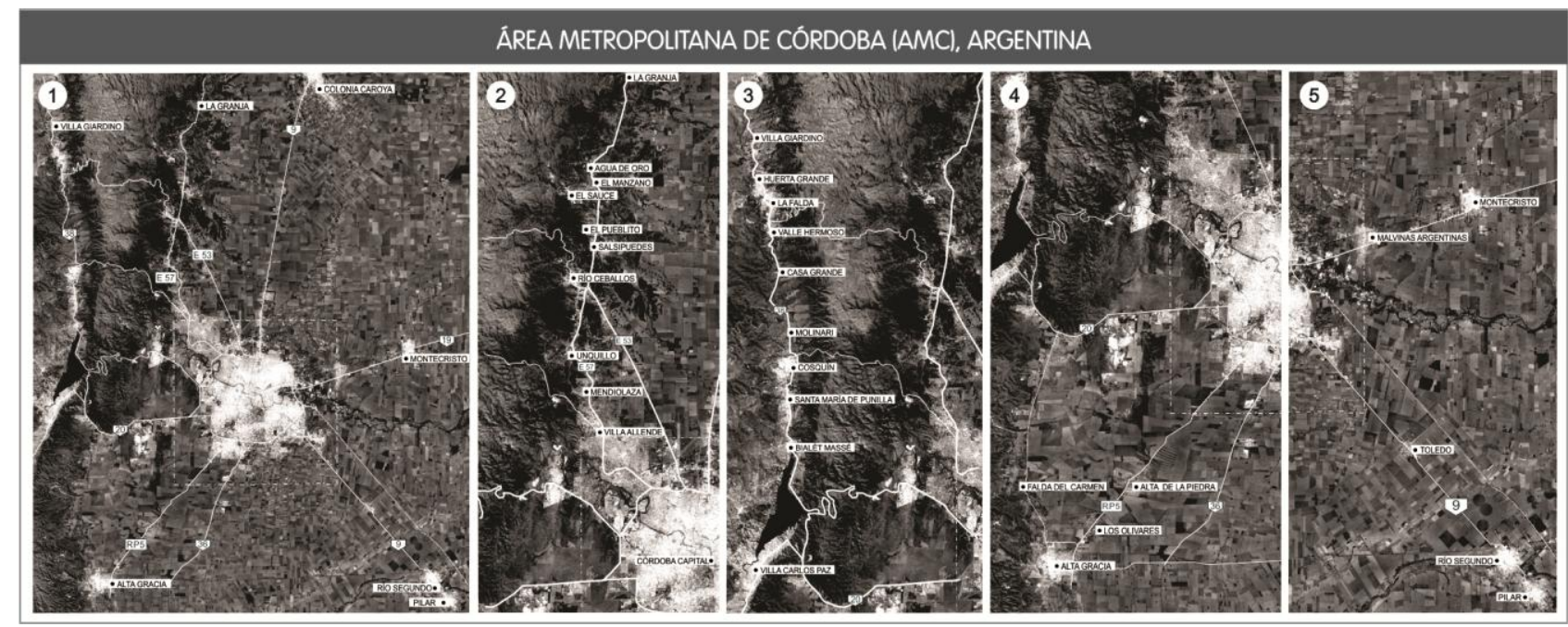

Gráfico 1. 1) Delimitación del AMC y radio municipal de la capital. 2) Corredores E- 53 y E- 57. Conurbación de las Sierras Chicas 3) Ruta Nacional №38. Centros eslabonados del Valle de Punilla. 4) Ruta Provincial. ํ⒌ Zona de Paravachasca 5) Ruta Nacional N9 Norte. Poblados 6) Ruta Nacional № 9 Sur. Poblados. Fuente: Elaboración propia a partir de Google Earth Pro. 
Morfológicamente, se desarrolla en fragmentos urbanos en reemplazo de la ciudad tradicional, por medio de trazados predominantemente regulares en áreas de llanura, y no regulares u orgánicos en terrenos con variaciones topográficas. Como rasgos comunes se evidencia la existencia de ingresos restringidos con control permanente, normalmente uno, y la disposición central o en posiciones topográficamente dominantes de las actividades complementarias en fracciones de suelo de superficies mayores. Las parcelas residenciales oscilan entre 250 y $2500 \mathrm{~m} 2$ según la localización y los ingresos económicos de sus residentes. La densidad poblacional es variable, con mayor número de habitantes en urbanizaciones de planicie próximas a la capital. El tejido conformado normalmente por viviendas unifamiliares de hasta dos niveles presenta, en áreas serranas, características de discontinuidad, con unidades residenciales ubicadas normalmente al centro de la parcela, y en terrenos de planicie, adquiere condiciones de continuidad y alineación al materializarse, en manzanas rectangulares de lotes entre medianeras con jardín y patio.

Se localizan en áreas suburbanas (gráfico 2a) a través de la expansión lineal - sectorial, en paralelo a las líneas de movilidad, y celular, a través de nodos comunicados por rutas y autopistas. Las UCS se manifiestan como una de las principales modalidades de producción del espacio habitacional periférico de las últimas dos décadas. Los cuadrantes NE y O son los principales receptores de este tipo de intervención destinado a sectores de mayor poder adquisitivo. En el periodo 1990 - 2001 (gráfico 2b), se observa una primera expansión, principalmente, dentro del ejido de la capital y en las ciudades conurbadas de Villa Allende, Saldán y Mendiolaza. A partir del 2001 emergen en municipios próximos, con distancias al centro de la capital entre los 15 y $25 \mathrm{~km}$, vinculadas a través de vías de tránsito rápido, caso de la autopista Córdoba- Villa Carlos Paz. Paralelamente, se incrementa el número de barrios cerrados en el corredor de las sierras chicas y entre las Rutas Provinciales E- 53 y E-57. En los últimos años se observa la expansión hacia el límite SE del AMC, hacia ciudades como Toledo y Río Segundo - Pilar.

Los desarrollos recientes y las facilidades o dificultades que ofrecen ciertas áreas para expandir sus límites urbanos a través de este patrón dan pautas sobre la tendencia de expansión (gráfico 2c). Se observa:

. El crecimiento, mayormente a través de este patrón, de las áreas urbanizadas sobre el acceso oeste, sobre Ruta Provincial $\mathrm{N}^{\circ} 20$, que conjuntamente con la delimitación de barrios cerrados aun no construidos y proyectos aprobados, constituyen un fuerte antecedente para determinar cómo tendencia el incremento de las UCS que podrían, en un futuro por continuidad, conformar una nueva conurbación.

. El establecimiento en los últimos años de UCS en el cuadrante NE, sobre ruta E-53 próximos a los nudos viales y sobre los caminos hacia Ruta Provincial E-57, marcan una fuerte tendencia de urbanización sobre las vías transversales de movilidad entre estas dos rutas, conformando linealidades que podrían extenderse a futuro con el establecimiento de nuevas vías de circulación o demandar su construcción.

. El desarrollo del patrón como células en ciudades más alejadas de la capital, principalmente en el cuadrante SE, podría deberse a la falta de disponibilidad de terreno, la creciente oposición a este tipo de urbanizaciones en entornos serranos y a la imitación de formas de vida. La calidad de los espacios abiertos, la distancia en tiempo a la fuente laboral, y en algunos casos, el menor costo por movilidad "liberada de peajes", han motivado y promueven su desarrollo sobre municipios de la red de acceso a Córdoba (RAC).

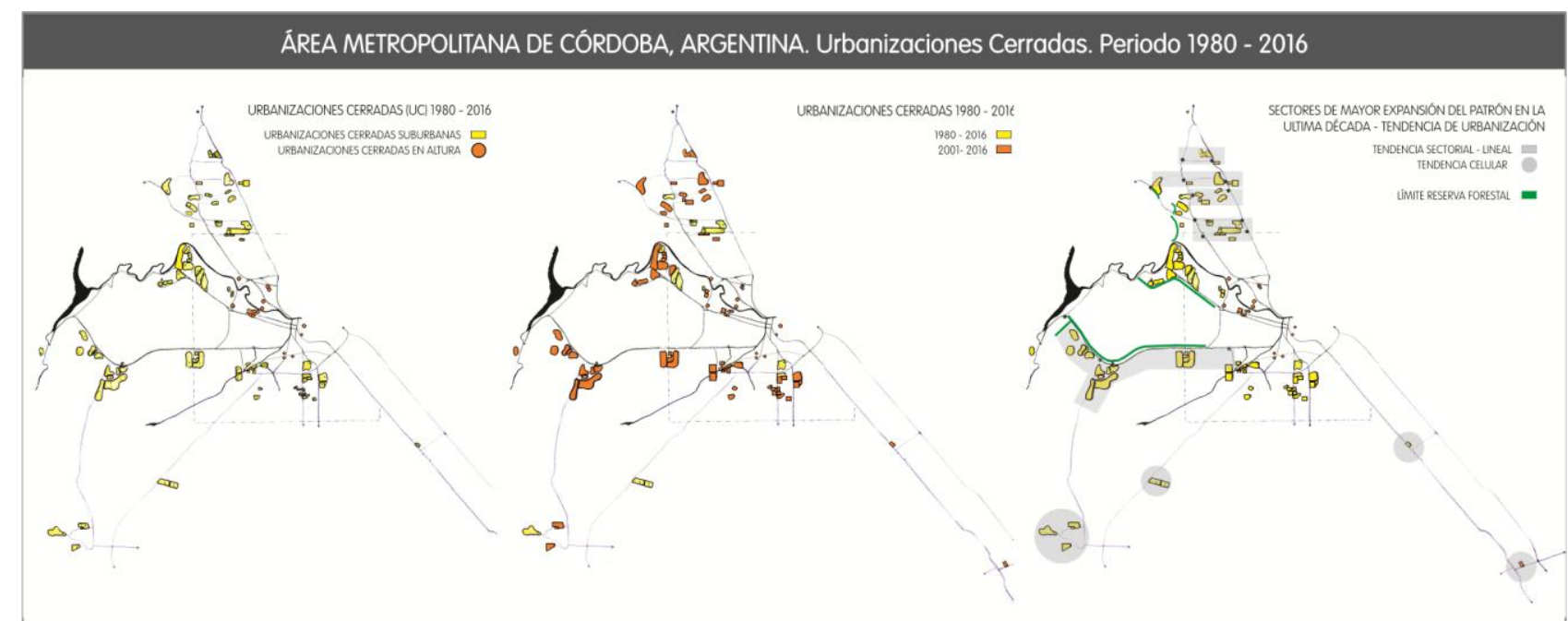

Gráfico 2. a) Localización de las UC. b) UC periodo 1990- 2001 y 2001 - 2016 c) Tendencias de expansión del Patrón. Fuente: Elaboración propia en base a Google Earth. Wikimapia.org. 
b) Urbanas. Condominios (UCC). Podrían ser definidos como edificios de departamentos con servicios de seguridad e instalaciones comunes para todos los habitantes. Localmente incluyen piscina, solárium, salón de usos múltiples, cocheras cubiertas, acceso restringido, perímetro controlado. En la capital se incorporan oficinas y comercios.

Este patrón de asentamiento se caracteriza por un uso de suelo dominante residencial de sectores con poder adquisitivo medio- alto y usos complementarios comerciales y de oficinas sobre arterias de movilidad. Internamente dispone de espacios abiertos parquizados con canchas de tenis, piscinas y quinchos equipados.

Morfológicamente se caracteriza por una altura mayor a la de su tejido circundante por medio de una forma urbana que difiere de la tradicional ocupando grandes parcelas vacantes, valiéndose del trazado de la ciudad. Constituyen un tejido de edificios exentos de altura entre 15 y 25 pisos. La densidad de este patrón varía según se trate de condominios en altura o urbanizaciones estilo casonas. Éstas últimas se materializan en 4 a 5 pisos, con servicios comunes en su parte central.

Por lo general, el patrón tiene lugar en la confluencia de variadas líneas de movilidad, en proximidad a la multiplicidad de actividades y en bordes de la ciudad capital sin llegar a desarrollarse en áreas suburbanas. En el AMC se visualiza en ciudades con mayor índice de crecimiento ya ocupadas con urbanizaciones cerradas diversas.

En base la expansión de las UCC en las últimas décadas, se podría determinar:

- Una fuerte tendencia a la ocupación de los polígonos y nodos estratégicos por medio de estos emprendimientos desarrollados por inversionistas privados, en contraposición a los conjuntos habitacionales anteriores al ' 80 donde predominaban las propuestas públicas y de cooperativas (Torres Alas III, Barrio Obras Sanitarias de la Nación, Barrios del Instituto Provincial de la Vivienda, entre otros).

- La tendencia al aumento de la densidad a través del incremento de altura, que comprometen la capacidad de las infraestructuras (movilidad, cloacas).

\subsection{ASENTAMIENTOS INFORMALES (AI)}

Las llamadas "villas de emergencia" constituyen una de las situaciones de informalidad de mayor presencia temporal y espacial en nuestro contexto. Monayar (2011) las describe como una forma de irregularidad urbana que supone transgresiones a los códigos urbanos civiles, que responden a procesos propios de sus residentes y requieren de actualización permanente del estado para su adecuación, regulación y solución. La imposibilidad de acceder a la vivienda y el suelo urbano, en términos planteados por el mercado o por el Estado, conducen al proceso de autoproducción (Borja, 2003), (Castells, 1981), (Clichevsky, 2000).

En el contexto local se caracterizan por un tejido heterogéneo, abierto y disperso de viviendas autoconstruidas de uno o dos niveles dispuestas, por lo general, sin seguir un esquema de trazado claro. El establecimiento sobre márgenes de cursos de agua o en intersticios en área de mayor consolidación urbana promueve formas de materialización diferentes según la situación. Los espacios ocupados por las viviendas son diversos, dada la autodefinición de los límites por parte de sus residentes según la disponibilidad o acuerdos entre vecinos.

La localización de este patrón se corresponde con factores que determinaron la lógica distributiva de los asentamientos por más de tres décadas (gráfico 4a y 4b) caracterizada, principalmente, por la ocupación en los bordes del perímetro urbano y en los márgenes de cursos de agua y vías férreas según el carácter dominial de las tierras. Avanzado el tiempo aumenta el número de asentamientos y el contacto con la ciudad formal por la extensión de la mancha urbana. A partir de los '80, el crecimiento de la ciudad evidencia un cambio en la lógica de ocupación con el establecimiento de las "villas" en intersticios de mayor consolidación urbana (gráfico 4c) dejando en evidencia la creciente demanda de suelo urbano de población sin posibilidad de acceso al mismo, por aumento demográfico, descenso social o sucesivas generaciones de población informal (Buthet, 2010).

La disposición geográfica del hábitat informal se ve alterado sustancialmente con la llamada política de formalización del Plan Provincial "Mi Casa, Mi Vida, 2003", que, pretendió dar solución a la situación de emergencia (desarrollado en el ítem siguiente). 


\subsection{POLÍtICAS HABITACIONALES PÚBLICAS Y CONJUNTOS RESIDENCIALES PARA SECTORES CON CAPACIDAD DE PAGO A LARGO PLAZO}

a) Políticas Habitacionales Públicas. Vivienda (PHPV). Lotes (PHPL): Se incluyen en este ítem los patrones de asentamiento producto de Políticas Habitacionales Públicas de gran impacto en la configuración de la ciudad en la última década; "Plan Mi Casa, Mi Vida" (2003) y el reciente Programa Provincial "Lo Tengo. El plan del lote propio" (2016). Se entiende como Política Pública aquella diseñada y gestionada a través de un gobierno y una administración pública con fines de satisfacer la necesidad de una sociedad, en este caso solucionar el problema habitacional de sectores vulnerables y clase media.

El Plan "Mi Casa, Mi Vida", se desarrolla en marco del "Plan de Modernización del Estado", y desde el Ministerio de Obras Públicas -Dirección Provincial de la Vivienda- y la Agencia Córdoba Ambiente, con financiamiento del Banco Interamericano de Desarrollo (BID). Surge como un proyecto de emergencia para la rehabilitación habitacional de grupos vulnerables que, en asentamientos precarios sobre los márgenes de los canales de riego, fueron afectados por las inundaciones del 2000 (Decreto $N^{\circ}$ 2565/01). Este plan derivó en la construcción de 19 barrios, 11 denominados "ciudades". El programa "Lo Tengo. El Plan del lote propio" es llevado a cabo por la Dirección del Ministerio de Vivienda, Arquitectura y Obras Viales y el Ministerio de Desarrollo Social de la Provincia de Córdoba. Tiene como objeto la transferencia de 30 mil lotes con infraestructura (13 mil en capital), destinados a familias no propietarias para la construcción de vivienda única.

El patrón de asentamiento derivado del "Plan Mi Casa, Mi Vida" se caracteriza por un uso de suelo dominante residencial, que en el caso de los Barrios Ciudades es complementado con equipamiento comunitario (jardín de infantes, escuela primaria, postal policial y dispensario) que ocupan aproximadamente el $5 \%$ de la superficie, y espacios verdes con fines recreativos - deportivos, en el $10 \%$ de la urbanización. El Programa "Lo Tengo. El Plan del lote propio" facilita la adquisición de parcelas urbanas en 8 barrios de la ciudad con destino a la vivienda unifamiliar, promoviendo un único uso de suelo.

Morfológicamente el patrón PHPV se caracteriza por un trazado regular de manzanas rectangulares de lotes iguales de $250 \mathrm{~m} 2$. La accesibilidad condicionada a la movilidad inmediata es, normalmente, a través de un punto principal. Las parcelas que alojan los equipamientos comunitarios han sido previstas, ubicándose normalmente en su parte central de modo lineal. El tejido resultante es de baja densidad (promedio $110 \mathrm{hab} / \mathrm{ha}$ ), dada la existencia de una única tipología de vivienda; unifamiliar de un nivel entre medianeras, con jardín y patio, de $42 \mathrm{~m} 2$ cubiertos, por debajo de lo exigido por el Código de Edificación de la Municipalidad de Córdoba. El Plan "Lo Tengo. El plan del lote propio" establece condiciones de urbanización estrictas, a través de una trazado regular, para dar cabida a un tejido de baja densidad constituido por viviendas unifamiliares.

Los barrios del Programa "Mi Casa, Mi Vida", se localiza en su mayoría en la periferia de la ciudad capital,

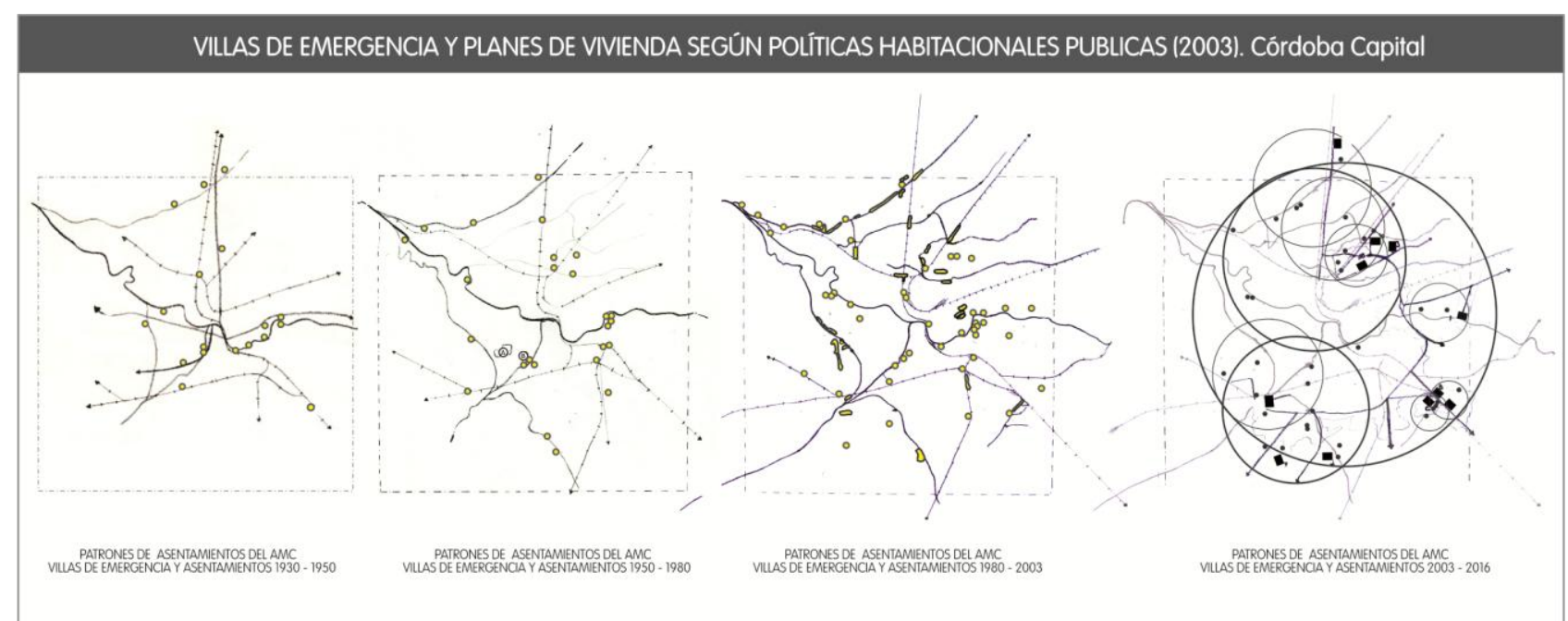

Gráfico 3. A, b y c) Localización de las "villas" según cortes temporales d) Asentamientos relocalizados en los $\mathrm{B}^{\circ}$ Ciudades. Elaboración propia según Plano de Localización de Vivienda Social 1981 - 2008, Ministerio de Desarrollo Social. Gobierno de la Provincia de Córdoba/ Plano de localización de Villas de Emergencia. Secretaria de Infraestructura, servicios públicos y ordenamiento territorial. Subsecretaría de Planificación e Integración urbana. Dirección de Urbanismo, Municipalidad de Córdoba / Irregularidad Dominial. Observatorio Urbano de Córdoba/ www.wikimpaia.org 
traspasando la Av. Circunvalación, en los cuadrantes NE, E y S (gráfico 3c) y solamente uno en el municipio colindante de Juárez Celman sobre Ruta $N^{\circ} 9$ Norte. El patrón tiene lugar a modo de células poco integradas a la estructura urbana. La población de estos barrios provienen de antiguas villas que han sido relocalizadas, cuya ubicación distan algunas hasta $15 \mathrm{~km}$ del las nuevas urbanizaciones (caso Barrio Ciudad de Mis Sueños sobre Ruta $N^{\circ} 9$ Sur). El plan requirió de la modificación de la regulación del suelo, dado la imposibilidad que establecía la misma de urbanizar a través de planes de vivienda. El criterio de erradicación extendido a otros sectores de la ciudad que no presentaban vulnerabilidad a los fenómenos climáticos y los posteriores desarrollos inmobiliarios en alguna de las áreas que el plan preveía "sanear" motivó la denuncia de "gentrificación" por parte de diversos autores. El hábitat periférico para sectores de ingreso económico bajo- medio promovido por el Estado sigue evidenciándose en los destinos seleccionados para el nuevo programa "Lo tengo El plan del lote propio" en los bordes de la capital traspasando los limites de Av. Circunvalación.

b) Cooperativas de Vivienda (COV): Podrían definirse como asociaciones de personas unidas voluntariamente, cuya administración y gestión se lleva a cabo a través de acuerdos entre los asociados para hacer frente a sus necesidades y aspiraciones de manera más ventajosa, en este caso en materia habitacional. Se toma de referencia para el análisis de este patrón de asentamiento la Cooperativa Horizonte Ltda., dada su trayectoria en el mercado local y el importante número de conjuntos habitacionales producidos, superando las 11 mil unidades construidas. Esta cooperativa se define como autofinanciada por sus asociados con objeto de suministrar viviendas a través del fraccionamiento de tierras, dotación de infraestructuras y producción de materiales en planta fabril propia.

Materializa un uso de suelo urbano monofuncional residencial por medio de conjuntos habitacionales para la clase media con capacidad de pago en el largo plazo que no cumplen con los requisitos para acceder a créditos bancarios o propuestas públicas.

Morfológicamente se caracteriza por un tejido de baja densidad, constituido por viviendas unifamiliares de un solo nivel en cinco tipologías diferentes, de superficies entre los 30 y $92 \mathrm{~m} 2$ cubiertos con posibilidades de ampliación, en lotes de entre 150 a $250 \mathrm{~m} 2$. El trazado que posibilita este tejido es regular, de manzanas rectangulares, con lotes estándar de acuerdo a la tipología de vivienda a construir.

Los conjuntos de viviendas se ubican en los bordes internos de Av. Circunvalación y en la periferia, principalmente al noroeste; en la mayoría de los casos, limitados por barrios de vivienda social y consolidando vacancias o constituyendo células en áreas periféricas. La cooperativa se abastece de tierras a bajo costo, esto marca una tendencia de expansión del patrón a suelos urbanos periféricos dado el menor valor del mismo. Por medio de la ordenanza de Convenios Urbanísticos, vigente en la ciudad a partir del 2013, la cooperativa logra el cambio de suelo para habilitar la construcción de 2.300 lotes bajo este patrón en el cuadrante SE (Convenio Carrara de Horizonte) y en el NE (Villa Retiro del Horizonte).

ÁREA METROPOLITANA DE CÓRDOBA, ARGENTINA. Politicas Habitacionales Públicas (PHP) y Cooperativas de Vivienda (COV). Periodo 1980 -2016

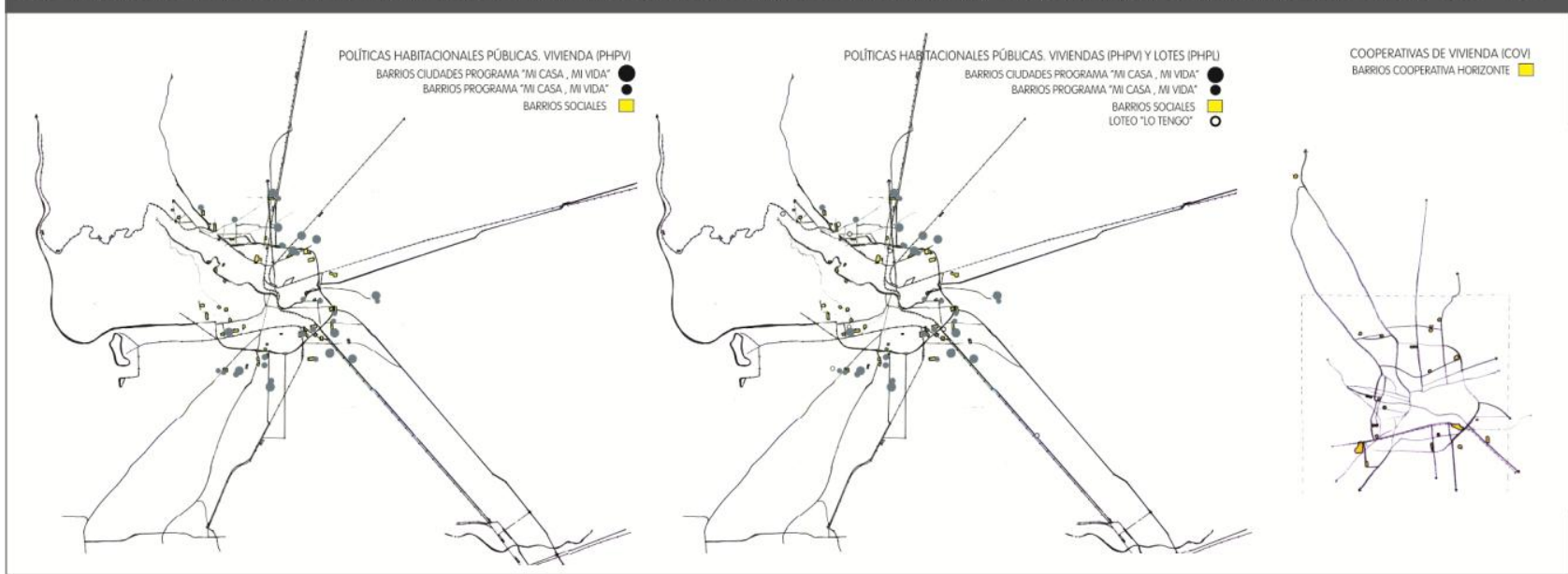

Gráfico 4. a) B Programa Mi Casa, Mi Vida. 2003 b) Políticas Habitacionales Públicas. Viviendas y lotes c) Conjuntos Cooperativa Horizonte. Elaboración propia según Plano de Localización de Vivienda Social 1981 - 2008, Ministerio de Desarrollo Social. Gobierno de la Provincia de Córdoba/ Plano de localización de Villas de Emergencia. Secretaria de Infraestructura, servicios públicos y ordenamiento territorial. Subsecretaría de Planificación e Integración urbana. Dirección de Urbanismo, Municipalidad de Córdoba / Irregularidad Dominal. Observatorio Urbano de Córdoba/ www.wikimpaia.org / lo tengo.cba.gov.ar / www.coophorizonte.com.ar 


\section{4 INDUSTRIA}

a) Cinturón de Industria Diversificada. Comprende las actividades económicas que impliquen uso del suelo industrial o asimilable, compatible en proximidad con el uso de suelo residencial. Conforme a su impacto ambiental son consideradas inocuas, resultan inofensivas para el entorno siendo compatibles con el resto de las actividades humanas; ó tolerables, producen efectos contaminantes fácilmente corregibles (Ordenanza 8133/85. Municipalidad de Córdoba).

El patrón se conforma, principalmente, por actividad industrial basada en la producción de bienes, transformación - física o química- o refinamiento de sustancias -orgánicas o inorgánicas, montaje o ensamblaje de componentes y fraccionamiento, industria alimenticia y distribución.

Se caracteriza por su conformación lineal, resultado de la sumatoria de lotes en los bordes de las rutas, avenidas y caminos, por medio de un trazado irregular de parcelas de entre 2 y 4 ha desiguales con frente hacia las vías de movilidad. Integran también este patrón áreas de mayor antigüedad de entre 50 y 80 has, correspondientes a la industria automotriz de la primera y segunda fase de industrialización El tejido, de entre 10 y $15 \mathrm{~m}$ de altura, se lee heterogéneo y abierto.

La lógica de expansión del patrón sigue las vías de movilidad vehicular de la RAC, y las líneas férreas (gráfico 5a). La conformación resulta claramente lineal al sur de la capital sobre avenida circunvalación y en fragmentos de las rutas nacionales. Debido a su expansión, al norte se percibe como un área de bordes definidos por los caminos vinculados a la red de acceso a la capital. Las industrias automotriz y de aviación, por su existencia previa a la conformación del cinturón o anillo fabril responden a otra lógica de asentamiento, vinculadas más claramente a los predios ferroviarios, caso de Fiat al SE y Renault al SO.Las tendencias de crecimiento (gráfico $5 \mathrm{~d}$ ) pueden leerse más claramente hacia el norte, donde tiende a consolidarse por medio de actividades que demandan parcelas de superficies entre 1 y 2 has y expandiéndose más allá de los bordes de movilidad constituyendo un área fabril.

b) Nodos de Alto Impacto. Se engloban en esta categoría las actividades industriales susceptible de provocar conflictos funcionales de significación en el conjunto urbano, en razón de su tamaño, volumen, rubro y/o tipos de procesos utilizados. Conforme a su impacto ambiental se consideran molestas - producen daños, incomodidad y efectos contaminantes corregibles a alto costo-, nocivas -producen daños, perjuicios y perturbaciones o efectos tóxicos o perniciosos - y peligrosas, inflamables o explosivas - ocasionan riesgos 0 inseguridad eminentes por explosiones, combustibilidad, inflamabilidad o toxicidad-. Particularmente a fines de esta investigación se incluyen las actividades: extractivas, cortaderos de ladrillo, refinamiento de combustible, tratamiento de efluentes, frigorífico, avícola, enterramiento o tratamiento de residuos.

Sus características morfológicas varían de acuerdo a la actividad, desde predios destinados al depósito de residuos orgánicos, inorgánicos y químicos de superficies entre 50 y 150has algunos con barrera forestal, instalaciones para criadero y faenado e infraestructuras para refinamiento de combustible y tratamiento de

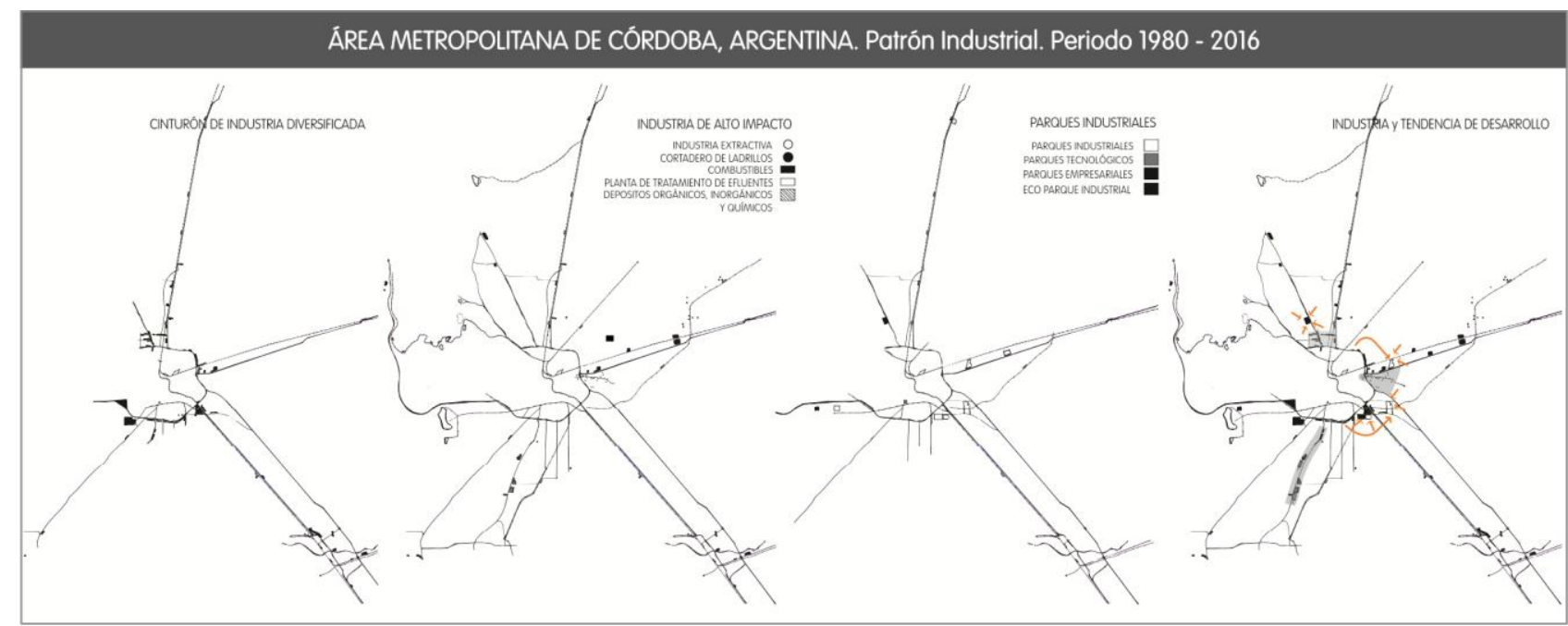

Grafico 5. a) Cinturón fabril de Córdoba b) Polígonos de Alto Impacto AMC c) Parques y polígonos industriales d) tendencia de desarrollo. Fuente: elaboración propia según Crisafulli, Baralla (2001) / infonegocios.info / impulsonegocios.com / comercioyjusticia.info / www.energiverde.com / cedu.com.ar / wikimapia.org 
efluentes. En todos los casos, las construcciones son exentas, rodeadas por lo general, de suelo no urbano.

La lógica de expansión del patrón (gráfico $5 \mathrm{~d}$ ) es determinada por la distancia a los suelos residenciales. En el caso de los depósitos de residuos, los predios se localizan en suelos rurales sobre las vías de acceso SE, concentrando varias tipologías que implican entierro o tratamiento. Los criaderos avícolas y frigoríficos se localizan mayormente en otras ciudades del AMC en relación a cursos de agua. La actividad extractiva y cortaderos de ladrillos evidencian una lógica de asentamiento vinculada a cortes temporales anteriores, con puntos extractivos próximos o sobre las áreas serranas y relacionados con las vías férreas.

c) Parques y Polígonos industriales: "Se considera parque industrial a toda extensión de terreno urbanizado, dotado de infraestructura y servicios comunes necesarios para el establecimiento y evolución de las industrias que en él se instalen". (Ley Provincial $N^{\circ}$ 7.255/85). Localmente existen cinco tipologías establecidas, en proyecto o construcción: industrial, empresarial, industrial- tecnológico y científicotecnológico y el proyecto del Eco Parque Industrial de Córdoba (EPIC).

Morfológicamente, para parques industriales, la ley especifica sus características en: accesos y calles internas afirmadas e iluminadas, lotes trazados y aterraplanados y cinturón verde perimetral de $20 \mathrm{~m}$ mínimo. El trazado debe complementarse con infraestructuras y servicios de agua industrial, contra incendios y para servicios generales, desagües pluviales y/o cloacales, planta de tratamiento de efluentes, abastecimiento y distribución de energía eléctrica y gas. Este patrón se caracterizan por poseen un trazado regular con lotes de superficies variables con frente a las calles y accesos vinculados a la RAC y vías férreas. El tejido resulta abierto y de $10 \mathrm{~m}$ de altura aproximada. Si bien el parque científico- tecnológico de la Universidad Nacional de Córdoba se incluye en este patrón, cabe mencionar que morfológicamente resulta diferente materializándose en un edificio de $1.400 \mathrm{~m} 2$ en tres plantas.

La ubicación de los parques es periférica. El patrón de desarrollo sectorial- nodal está vinculado a múltiples vías de movilidad, aunque no directamente en sus bordes. En su conjunto, los siete parques de la capital implican aproximadamente $360 \mathrm{ha}$ disponibles. En el resto del AMC, se visualizan el "Parque Industrial Mi Granja" sobre Ruta Nacional №19, de 200has de producción diversificada y el proyecto "Polo 52", de 52ha, en la localidad de Pilar. Se incluyen, además, las áreas de desarrollo tipo "célula" de industria diversificada, entre las que podrían mencionarse las de Malagueño (Área industrial Minetti, en construcción, de 15has, privada y el Polo industrial Malagueño, en construcción, de 10has, municipal), y Colonia Caroya (proyecto, municipal, de 16has). La tendencia observada (Gráfico $5 \mathrm{~d}$ ) es la consolidación y consecuente recesión en la expansión lineal industrial, dada la situación de irregularidad de numerosas firmas que debieran reubicarse siendo los parques la opción más ventajosa por las facilidades ofrecidas. La consolidación es motivada por medio la Ley de Promoción Industrial de la Provincia.

\section{5 ÁREAS COMERCIALES Y DE ENTRETENIMIENTO}

Nodos de servicios banales: En este patrón se incluyen las actividades vinculadas al llamado terciario "banal" de servicios a las personas; grandes superficies comerciales acompañadas de instalaciones para el ocio y gastronomía, denominadas normalmente como malls.

El uso de suelo dominante es el comercio y los servicios relacionados al ocio. Estos edificios poseen tiendas comerciales relacionadas con el rubro indumentaria, calzado, juguetería, decoración y electrónica. Como actividades de esparcimiento se incluyen cine, sala de juegos y espacios destinados a la gastronomía.

Morfológicamente se distinguen por ser edificios de más de un nivel, con seguridad perimetral y amplios espacios de aparcamiento.

Se localizan (gráfico 6a) en las principales vías de acceso a la ciudad en los cuadrantes NE y SE y en "nodos estratégicos" (Plan Director 2020). Este patrón se expande según un proceso de descentralización de parte del terciario de servicios estrechamente ligados a las nuevas zonas residenciales, en emplazamientos de alta accesibilidad territorial y exponibilidad a las infraestructuras arteriales -autopistas, autovías, carreteras principales- y sus lugares estratégicos -salidas, enlaces, cruces, estaciones- (Font, 2003). Las localizaciones responden a la lógica habitual de proximidad a los consumidores, primero en los centros urbanos y después en los asentamientos dispersos de las periferias, sumada a la lógica de emplazamiento estratégico a nivel territorial, buscando la máxima accesibilidad a todos los puntos del territorio y la fachada a los canales de los flujos más importantes, entendiendo la centralidad como pertenencia a una red" (Dematteis, 2001). 


\section{EL MODELO DE LA FRAGMENTACIÓN EN EL AMC}

Como se mencionara en la introducción del presente artículo, el modelo de ciudad - región actual encuentra su base explicativa en dinámicas que globalmente empiezan a insinuarse en los '70 con el inicio de una nueva etapa conocida como capitalismo global, y se acentúa en los años '90 producto de la convergencia de la universalización del neoliberalismo y del paradigma socio cultural posmoderno, que como reafirman Cicolella y Magnaqui (2009) promueven una Transición del proceso de Urbanización, generando nuevas formas territoriales particularmente en las regiones metropolitanas. Estas nuevas formas dan lugar a un modelo físico- espacial de ciudad, donde la fragmentación caracteriza el hecho urbano- territorial en la fase más reciente del desarrollo de América Latina (Borsdorf, 2003).

Cómo se ha demostrado mediante el análisis de los patrones de asentamiento, las dinámicas que han promovido la expansión del AMC han desdibujado la tradicional estructura mono céntrica de la capital dando lugar a una ciudad- región fragmentada (gráfico 7a). El proceso de expansión física y funcional de la ciudad, se videncia en la multiplicidad de elementos económicos y habitacionales dispersos que se aíslan uno de otros a modo de células en la periferia. El modelo de la fragmentación sucede por medio de patrones de asentamientos que expanden el perímetro urbano con falta de consolidación de áreas intersticiales y sectores urbanos desvinculados de áreas consolidadas.

Las principales características de la fragmentación se evidencian en nuestro contexto por medio de:

- Elementos celulares habitacionales en la periferia; la distribución espacial de los conjuntos habitacionales, tanto de sectores vulnerable como aquellos con poder adquisitivo alto, dejan en evidencia el incremento de la suburbanización y de la polarización social (gráfico 6c);

- Sub centros periféricos de servicios; relacionados con la descentralización del consumo en una aparente tendencia al policentrismo, vinculados con los barrios de estratos altos (gráfico 6b);

- La Libre distribución de las zonas industriales; a través de nuevos patrones, como los parques industriales, que evidencian la pérdida de importancia del contacto directo con las líneas de transito interurbano como factor de localización dominantes -recordando la típica conformación de la ciudad que se extendía como mancha de aceite con áreas industriales sobre los corredores- (gráfico 6d);

- El aumento en extensión y magnitud de la red de movilidad; que promueve directamente la expansión por medio de las formas de estructuración espacial vigentes; la sectorial - lineal y la celular. El incremento de la circulación automotriz y la velocidad del tránsito, son determinantes de la urbanización en zonas periféricas y periurbanas, dado que el automóvil es el principal agente urbanizador del periodo.

- Consumo elevado de suelo: producto del uso ineficiente de las áreas urbanizadas y de la consideración del espacio libre como disponible para futuras urbanizaciones.

Las particularidades locales se corresponden con patrones de configuración socio -espaciales comunes a las ciudades latinoamericanas que, según Jarmillo, S. (1999), se caracterizan por un área central, con gran vitalidad urbana y concentración de actividades, un eje de crecimiento donde se localizan los sectores de más alto ingreso y una periferia pobre.

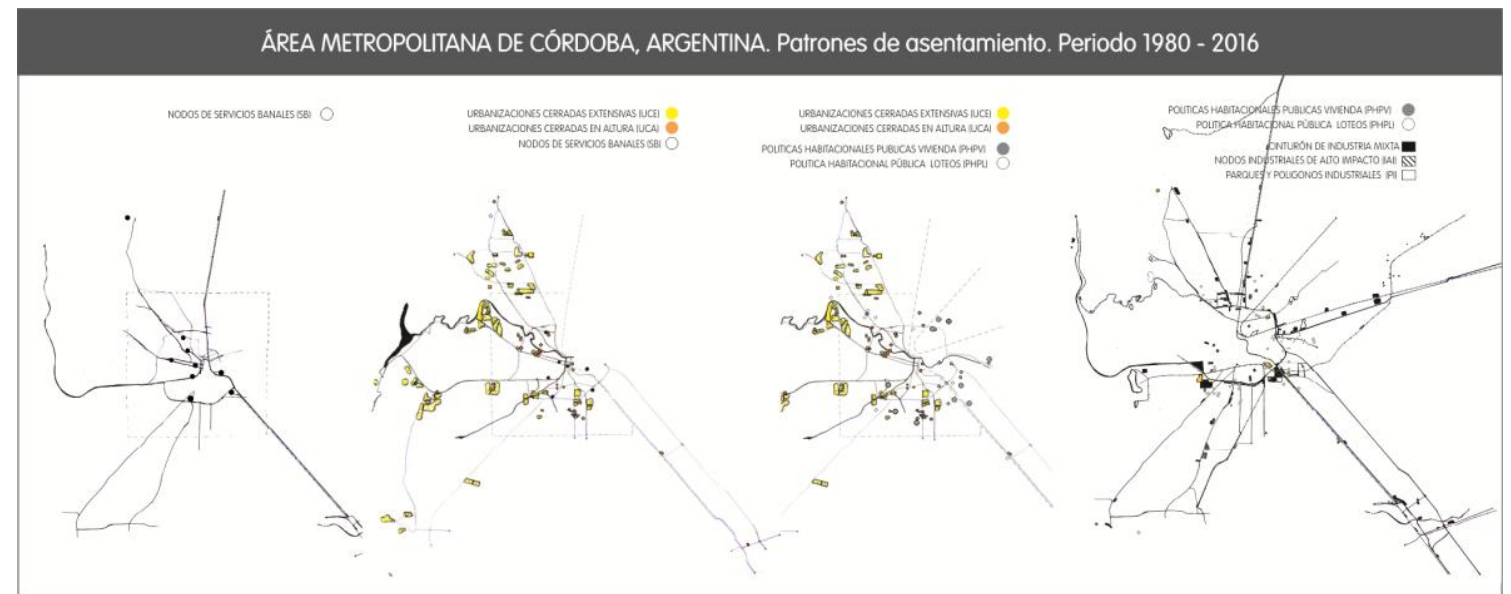

Gráfico 6. a) Nodos de servicios banales (NS) b) NS y UC c) hábitat periférico d) Periferia que concentra industrias de impacto, PHV y PHL. Fuente: elaboración propia. 


\section{MOTIVACIONES Y CONSECUENCIAS DEL MODELO DE LA FRAGMENTACIÓN}

Los costos para el conjunto urbano derivados del modelo fragmentado o disperso responden en su mayoría, a cuestiones de índole económico donde las lógicas de expansión parecen ser orientadas por "la fluidez del capital y la libertad creciente del mismo como ordenador territorial, sin mayores mediaciones en los procesos de decisión y ejecución de las políticas territoriales" (Vainer, 2000). Localmente se evidencia:

5.1 Suburbanización segregada: el mapeo de los patrones relacionados con el suelo residencial evidencia el desarrollo urbano desigual de los diferentes sectores y la polarización social creciente de la última década, con clases sociales de alto poder adquisitivo al NE y $\mathrm{O}$ de la ciudad y clases bajas en los cuadrantes opuestos (gráfico 6c). Al estudiar el desarrollo del hábitat periférico cordobés se pone en relieve que "en un contexto de alta inequidad social, el crecimiento por extensión intensifica la segregación residencial socioeconómica e incrementa la inequidad espacial" (Marengo, Monayar; 2012). La modalidad de producción del espacio habitacional ocurre, principalmente, a través de dos patrones de asentamientos; las UC como producto del mercado inmobiliario en el marco de políticas neoliberales y las COV y PHP como modalidad de contención de población frente a la imposibilidad de acceder a la ciudad consolidada.

El desplazamiento de sectores con poder adquisitivo a la periferia, afecta al conjunto urbano dada la reducción en la demanda de servicios y equipamientos. Paralelamente, favorece el establecimiento de nodos privados comerciales y de servicios vinculados a la satisfacción de las necesidades de este grupo social. La consolidación de "espacios de autoexclusión" y "de excluidos" (Marengo, 2003) desalientan el intercambio social, aumentan el nivel de prejuicio y fobia de seguridad promoviendo aun más el aislamiento, "sustrayendo a la ciudad su principal razón de ser; un lugar para el encuentro y el intercambio" (Folch; 1999). La localización periférica de urbanizaciones cerradas a modo de células con vacios intersticiales, además, promueven los niveles de especulación a través de la retención de suelo a la espera de la extensión de infraestructura para el suministro de urbanizaciones más alejadas. Lo anteriormente expuesto deja en descubierto la segregación residencial, como resultado de la dinámica propia del mercado de tierras y la baja capacidad por parte del estado para evitarla.

Numéricamente el fenómeno de la polaridad se expresa a través de 4.937 viviendas en los barrios ciudades del Programa "Mi Casa, Mi Vida" ubicados en la periferia, la mayoría a distancias de más de $20 \mathrm{~km}$ del centro de la ciudad. Si se considera un grupo familiar promedio de 5,59 miembros ${ }^{4}$ se estima un desplazamiento de aproximadamente 27.600 personas a la periferia desde sus originales lugares de residencia, muchos de los cuales con alto valor de suelo. Una dinámica de "guetización" o "re diagramación inmobiliaria de la ciudad tomando como punto de partida su compromiso asistencial para con los más pobre de la ciudad" (Boito, S/F). El fenómeno se incrementa con el aumento de 109,25ha hacia finales de los '90 a 482ha en el 2011; de los procesos de informalidad, villas, loteos fraudulentos, asentamientos, y tomas de tierras. En el otro extremo, los procesos de migración interna no forzada a través de la residencia en UCS se evidencian en al aumento poblacional de ciudades limítrofes y en el crecimiento desacelerado de la capital (8,9\% al 3,39\% en los periodos intercensales 1991-2001 y 2001-2010 respectivamente).

Los instrumentos de gestión que pudieran ser útiles en la recesión de este fenómeno se han debilitado recientemente por medio de una serie de medidas desafortunadas como la sanción de la ordenanza de "Reserva de Inmueble con Destino Social" en diciembre del 2016, posterior al pedido vía amparo a la municipalidad en octubre del mismo año de aplicar lo reglamentado por el Banco de Inmuebles (www.diaadia.com.ar; 26/10/2016). En comparación con la ord. №11.988 del "Banco de Inmuebles" se reduce los impuestos a las empresas constructoras del $5 \%$ al $2 \%$ con carácter de retroactividad implicando la devolución de fondos con destino a la vivienda social a los desarrollistas inmobiliarios que hayan hecho urbanizaciones a partir del 2011 (www.latinta.com.ar; 16/12/2016).

5.2 Desequilibrios territoriales relacionados a la localización de proyectos de inversión privada: EI poder de las empresas privadas sumado a la crisis de la planificación acontece en la elección, con pocas restricciones, de las áreas de desarrollo capitalistas. Muchas de las mismas en espacios de valor estratégico dada sus condiciones dimensionales, funcionales y de localización. Áreas determinadas en el Plan Director 2020 como de "oportunidad para que el Estado juegue como actor pro activo anticipándose mediante acciones sobre el territorio con proyectos complejos y mixtos", "con enfoques de heterogeneidad y equilibrio, que respeten los aspectos estructurales del territorio y las preexistencias, bajo los fundamentos de inclusión y sustentabilidad (Plan Director 2020; 100). La falta de regulación conduce a la promoción de

${ }^{4}$ El grupo familiar promedio de Córdoba está estimado en 3,2 personas, sin embargo para este grupo social Buthet (2010) lo considera en 5,2 miembros. 
determinados sectores urbanos y a la relegación de otros primordiales en el desarrollo de la ciudad. Tal situación se corresponde con la mayor autonomía del sector privado para la materialización de las propuestas debido a la capacidad de afrontar los costos de la urbanización y las facilidades ofrecidas a los inversionistas a través de un cuerpo normativo de flexibilidad creciente. La ordenanza $\mathrm{N}^{\circ} 12.077$ denominada "Convenios Urbanísticos" ha promovido propuestas polémicas en los últimos años. La misma implica un acuerdo entre la Municipalidad de Córdoba, que aplica cambios en la ordenación urbanística, y el propietario que debe garantizar en contraprestación un beneficio urbanístico para la ciudad.

Bajo esta figura podría mencionarse el proyecto sobre el polígono estratégico "Cruz Roja" del Ex Batallón 141 de la corporación América del Grupo Eurlekian y el "Convenio Los Ombúes" en el Polígono de "SachiCarrara" en el suroeste de la ciudad. El primero implica la edificación de $446 \mathrm{mil} \mathrm{m2} \mathrm{en} 22$ ha posibilitado por cambio de uso de suelo de reserva verde a mixto con torres de hasta $22,5 \mathrm{~m}$ de altura. Un proyecto que, según los representantes de la Red Ciudadana Nuestra Córdoba en la audiencia pública del 2016, incumpliría los marcos normativos del propio convenio "superando el FOS Y FOT establecidos de 0.4 y 2 a 0.83 y 4,7", "incrementando en 10 veces la densidad poblacional del sector" incorporando 13.984 habitantes, y dando lugar a un "espacio verde restringido, no respondiendo a lo establecido en el convenio de ponderar a la continuidad de los espacios verdes del Parque Sarmiento, entro otras irregularidades (www.Agenda4p.com; 7/08/2016)

5.3 Pérdida de identidad social de las ciudades dormitorios: los procesos de conurbación y la residencia fuera del ejido de Córdoba de personas cuyas fuentes laborales se establecen en la capital, promueve el carácter de ciudad dormitorio de municipios vecinos y la pérdida de identidad social del grupo ciudadano. Los municipios que más crecimiento intercensal han evidenciado en el periodo 2001-2010, son los ubicados a una distancia del centro de hasta $30 \mathrm{~km}$, caso de Saldán con un aumento poblacional del $400 \%$, Mendiolaza con $145 \%$ y Malagueño con $110 \% 5$. La expansión del patrón de UCS en ejidos próximos, responde a una tendencia de imitación de modelos de hábitat que ha llevado a la pérdida de las expresiones regionales.

5.4 Deficiencia en la red viaria y el transporte público: El aumento de la flota de automóviles y de la cantidad de viajes diarios a la capital en los últimos años ha agravado las problemáticas relacionadas con la congestión en las vías de acceso a la capital y los mayores costos del trasporte público de pasajeros. El incremento de la movilidad privada y de la distancia residencia- fuente laboral, promueve un transporte ineficiente dado el aumento del recorrido y la menor cantidad de pasajeros, relación estimada por la Secretaria de Transporte de la Municipalidad de Córdoba en 2,9 pasajeros por kilómetro (Municipalidad de Córdoba, 2014;43). La creciente dependencia de la capital de las ciudades limítrofes se evidencia en los datos de crecimiento del Parque Automotor, 68\% en el periodo 2000-2010, y del tránsito vehicular registrado en las rutas de ingreso- egreso. Según lo estimado por el IPLAM sobre las rutas RN20 y E-53 transita el $50 \%$ de los automóviles de la RAC, cuadrantes con barrios cerrados como patrón de crecimiento más notorio en las últimas décadas. El establecimiento de la clase media- alta en este extremo de la región ha acontecido en el aumento considerable de los desplazamientos cotidianos y la baja demanda de transporte público dada la disponibilidad de uno o dos autos por familia.

5.5. Deterioro del medio ambiente físico: La expansión urbana a través de los patrones antes descriptos, evidencia situaciones de conflicto en su relación con el sistema de espacios abiertos. La fragmentación trae como consecuencias disfuncionalidades medioambientales de diversos tipos de acuerdo a la dirección del crecimiento urbano. Las principales problemáticas surgen de la extensión sobre el cinturón fruti- hortícola y las reservas forestales serranas, principales estructuras ecológicas- productivas de la región.

a) Conflictos en situaciones de interfaz de la ciudad con terrenos productivos: principalmente en los cuadrantes NE y S de la ciudad, en contacto con el tradicional cinturón verde de producción fruti- horticola de la capital. La expansión urbana en terrenos productivos tiene lugar, principalmente, a través de conjuntos de viviendas sociales, asentamientos irregulares, nodos de alto Impacto relacionados con la actividad extractiva, combustibles en el cuadrante NE y depósitos de residuos al SO. La ampliación del límite urbano en esta dirección puede leerse como anexiones de suelo urbano que ha conducido a la perdida de las calidades naturales, económicas y sociales del medio rural. La inutilización y contaminación creciente de los canales de agua y la desaparición de suelos de mayor fertilidad hacen poco prospera la actividad motivando, ante la falta de respuesta por parte del estado, la venta de los terrenos para el loteo urbano ocasionando la perdida creciente de suelo productivo. Al respecto Giovellina (2002) en su estudio del

\footnotetext{
${ }^{5}$ Elaboración propia en base a Córdoba en cifras, Municipalidad de Córdoba 2014; 27.
} 
cinturón verde observa un uso del territorio sin respetar la organización precedente que rompe y destruye los sistemas ambientales, generando manchas y parches inconexos que terminan siendo inviables desde el punto de vista agrícola"; tal situación implica la "pérdida de capacidad local de producir alimentos, la ruptura de corredores biológicos y servicios ecosistémicos y la desaparición del patrimonio.

La latente amenaza de urbanizaciones especiales movilizó a una gran cantidad de actores sociales que, en esfuerzo solidario y recogiendo los reclamos de los productores, promovieron una serie de reformas normativas, entre las que se pueden mencionar la Ordenanza №11068/11 de transición - protección ambiental, que se suma a la Ord. №606/91 de la Municipalidad de Córdoba. Los principales motivos de defensa del sector fueron elevados al intendente de Córdoba por medio de la "Carta Abierta en defensa del cinturón verde" en mayo del 2016 con más de treinta instituciones adheridas, entre las que destacan el Instituto Nacional de Tecnología Agropecuaria (INTA), universidades, cooperativas y movimientos de agricultores.

b) Ruptura de los ecosistemas serranos. Las crecientes manifestaciones en contra de la urbanización sobre pies de montes que provoca la impermeabilización de suelos, la destrucción de flora y fauna y la contaminación y disponibilidad de agua evidencian la inconformidad del modelo urbano vigente de una gran parte de la ciudadanía. La masa arbórea que tiene por objeto regular el ciclo de agua y la biodiversidad se ha visto reducida drásticamente a causa de los incendios y el avance del suelo residencial sobre. En la década del ' 90 se perdieron 105 mil hectáreas de bosque a causa de los incendios y 42mil desde 2004 a 2013, situación que abrió paso a los desarrollos inmobiliarios que se multiplicaron en los últimos quince años según lo descripto por Deon (2015). La situación entra en contexto de la crisis nacional, siendo Argentina uno de los 10 países del mundo con más desmonte en los últimos años. A nivel local, ha acontecido un gran esfuerzo de resistencia ciudadana ante el intento de reformulación de la ley de bosques provinciales que implicaba el cambio de las áreas de reserva de conservación total a parcial, habilitación de fumigación aérea y minería en áreas de conservación, disminución de monto de multas, exclusión de figura de bosques nativos a los matorrales, entre otros aspectos. La oposición a la reforma se manifestó por medio de las asociaciones civiles, principalmente de los pueblos serranos, organizados bajo la "Coordinadora de la Ley de Bosques". La petición, que consiguiera aproximadamente 18.500 firmantes se manifestó en contra de lo que "conduciría a la destrucción de la mitad de los remanentes de bosques, profundizaría la grave crisis ambiental, agudizaría las inundaciones y aceleraría la desertización," y elevó el pedido de un espacio democrático que discuta la ley vigente (Ley 9814/2010).

La resistencia ciudadana al avance sobre las áreas naturales se evidencia en iniciativas entre las que se podrían mencionar, La oposición de vecinos de Saldán a la instalación de una cantera en la reserva hídrica Saldán Inchin y posterior aprobación de la Ordenanza №1/15 que prohíbe la instalación de canteras de todo tipo a cielo abierto, en la participación ciudadana en defensa del ambiente nativo frente a los desarrollos inmobiliarios. La protección de las reservas reglamentadas por decreto y el apoyo a las propuestas es uno

ÁREA METROPOLITANA DE CÓRDOBA, ARGENTINA. Relación del los SUT de las urbanizaciones y espacios abiertos. Periodo 1980 - 2016

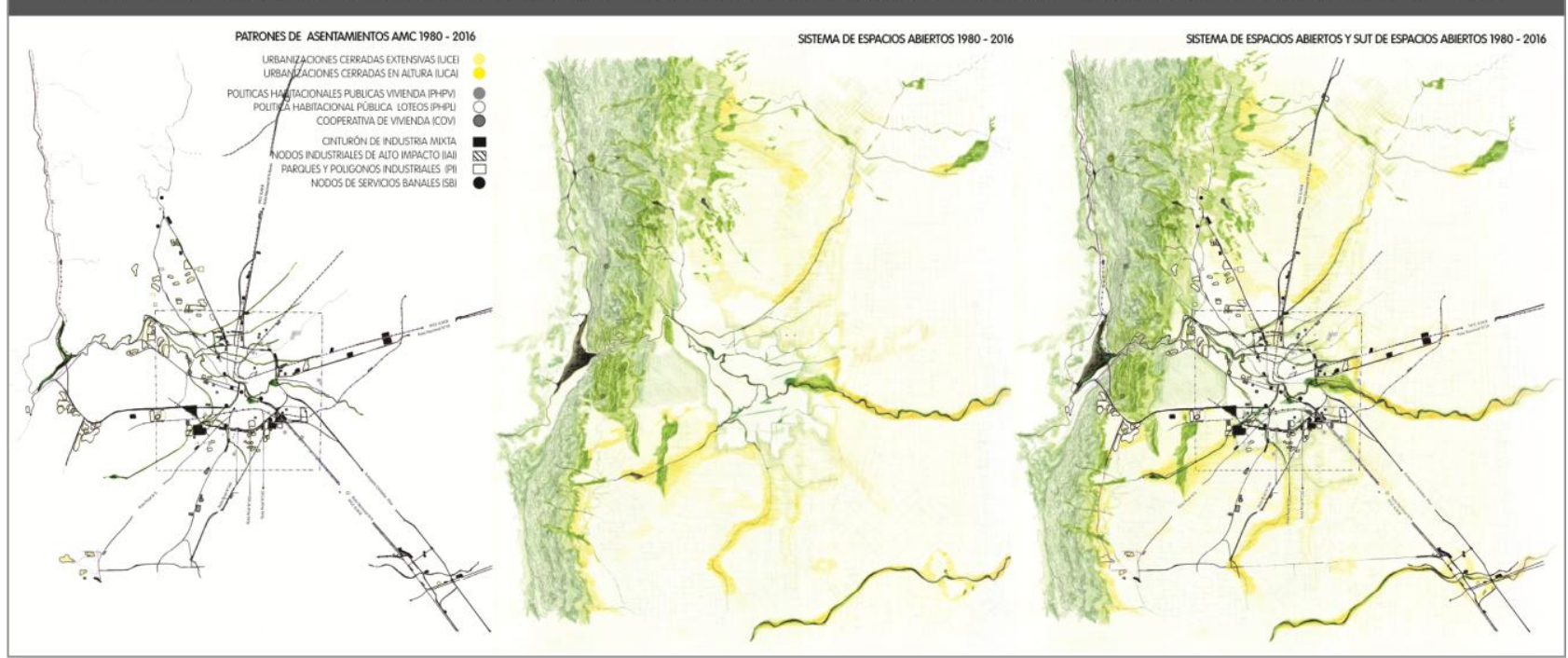

Gráfico 6. a) Patrones de asentamiento 1980- 2016 b) Sistema de espacios abiertos 1980- 2016 c) Superposición de ambos sistemas. Fuente: Elaboración propia en base a SAYAGO / SUELDO (1998) / IPLAM (2008) / IPUCOR / Observatorio de Agricultura Urbana, Periurbana y Agroecologica. AER INTA (2014) / www.cordobaturismo.gov.ar / www.wikimpaia.org 
de los principales motivos de lucha de la Coordinadora Ambiental de las Sierras Chicas, elevando un petitorio en el 2013 al gobernador de la provincia para "un proyecto de Corredor Hídrico Único y particular para las Sierras Chicas, a través de la herramienta de ordenamiento territorial participativo, como una propuesta macro pensada desde la ciudadanía". Anualmente la "Cruzada por las Sierras Chicas por la soberanía del agua y de la tierra" pretende concientizar sobre la importancia de la participación vecinal como instrumento de gestión del territorio.

Es necesario recalcar que las motivaciones al avance sobre el sistema de espacios abiertos en las sierras chicas no es solo proveniente del actor privado sino también del estatal, quien aprobara en agosto de 2016 el loteo para 92 viviendas, bajo el Programa "Lo Tengo.El plan del lote propio", en plena reserva Saldan Ichin reglamentada por decreto municipal $n^{\circ}$ 59/2001.

\section{A MODO DE CIERRE}

El estudio y representación gráfica del AMC a través de los SUT y los patrones de asentamiento ha permitido un arribo más claro a las problemáticas y temas emergentes que, impulsados o mitigados por circunstancias locales, definen las lógicas de consolidación y expansión de cada forma de crecimiento territorial.

La apropiación del área de estudio por medio del mapeo de las formas urbanas ha permitido tener dimensión de la problemáticas derivadas de la carencia de integridad en las operaciones de construcción del hecho urbano territorial. La amenaza a los ecosistemas naturales y la concientización de su funcionamiento sistémico ha instalado en la lucha ciudadana, el reclamo de herramientas de planificación supramunicipales.

El desarrollo del presente artículo pretende ser un aporte al conocimiento del territorio por medio, principalmente, de la representación gráfica. La lectura a través del dibujo ponderando las particularidades del sitio se considera una herramienta de valoración y proyecto dado que, como afirma Sabaté (2003) en la identidad del territorio esta su alternativa.

Es necesario instaurar en el ámbito académico y profesional la reflexión sobre los mecanismos de proyectación; dado que el arquitecto es el responsable de la configuración de las formas de crecimiento. La arquitectura de la ciudad no es la de sus edificios, ni sus espacios vacios, sino en la articulación de sus partes; proyectar las formas de crecimiento implica configurar un ritmo de tiempos que combine suelo, edificación e infraestructura (Solá- Morales; 1998).

ÁREA METROPOLITANA DE CÓRDOBA, ARGENTINA. Relación del los SUT de las urbanizaciones y espacios abiertos. Periodo 1980 - 2016

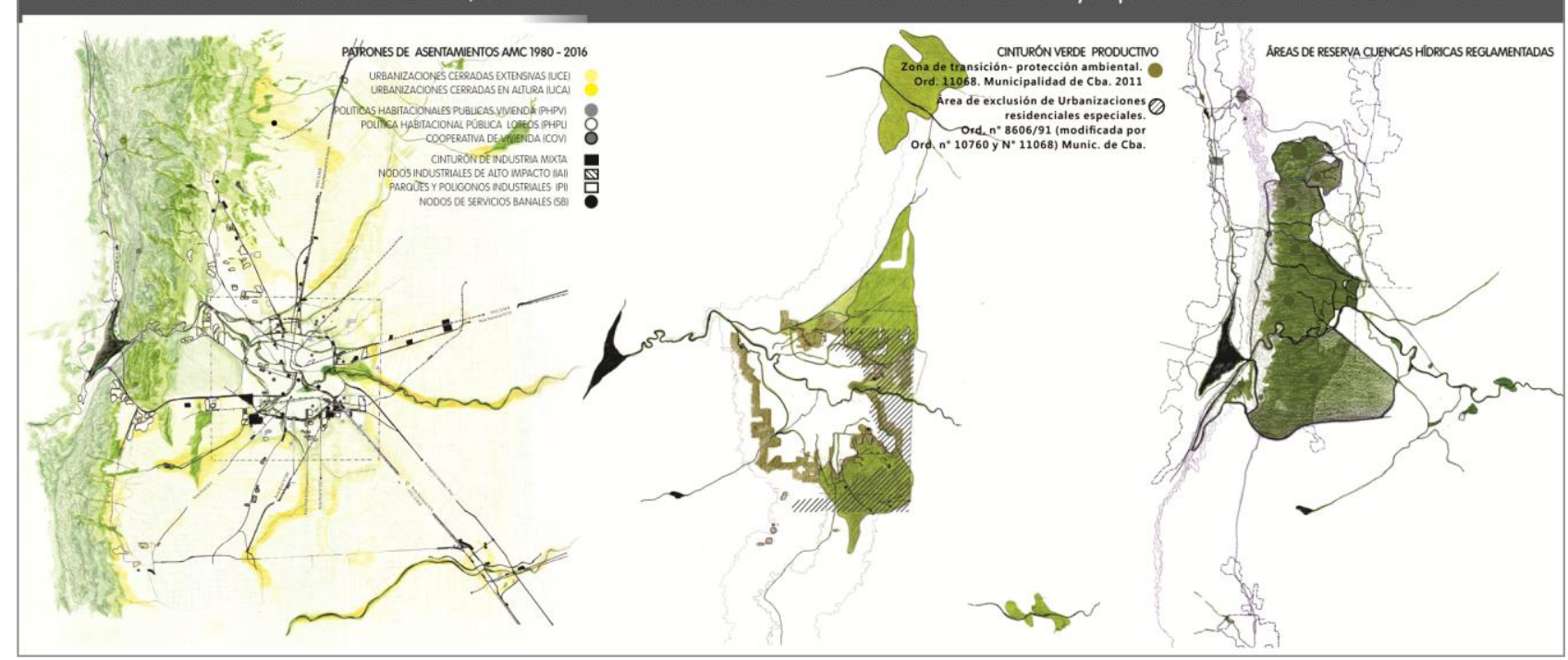

Figura 8. a) Patrones de asentamiento 1980- 2016 en relación al SUT de espacios abiertos 1980- 2016 b) Cinturón Verde productivo del AMC y ordenanzas vinculadas c) áreas de reserva reglamentadas. Fuente: Elaboración propia en base a SAYAGO / SUELDO (1998) / IPLAM (2008) / IPUCOR / Observatorio de Agricultura Urbana, Periurbana y Agroecologica. AER INTA (2014) / www.cordobaturismo.gov.ar / www.wikimpaia.org 
7. ANEXO GRAFICO 


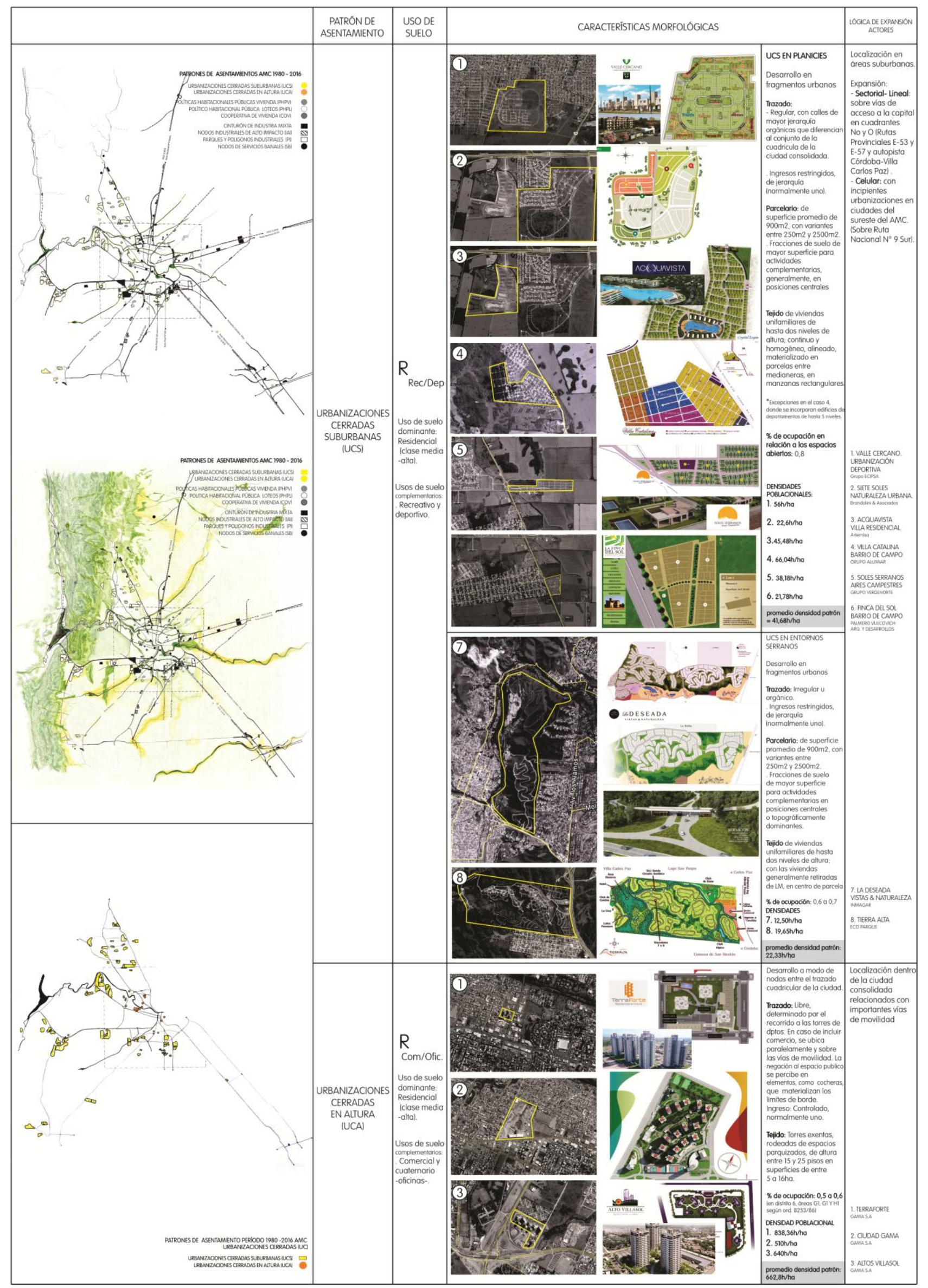




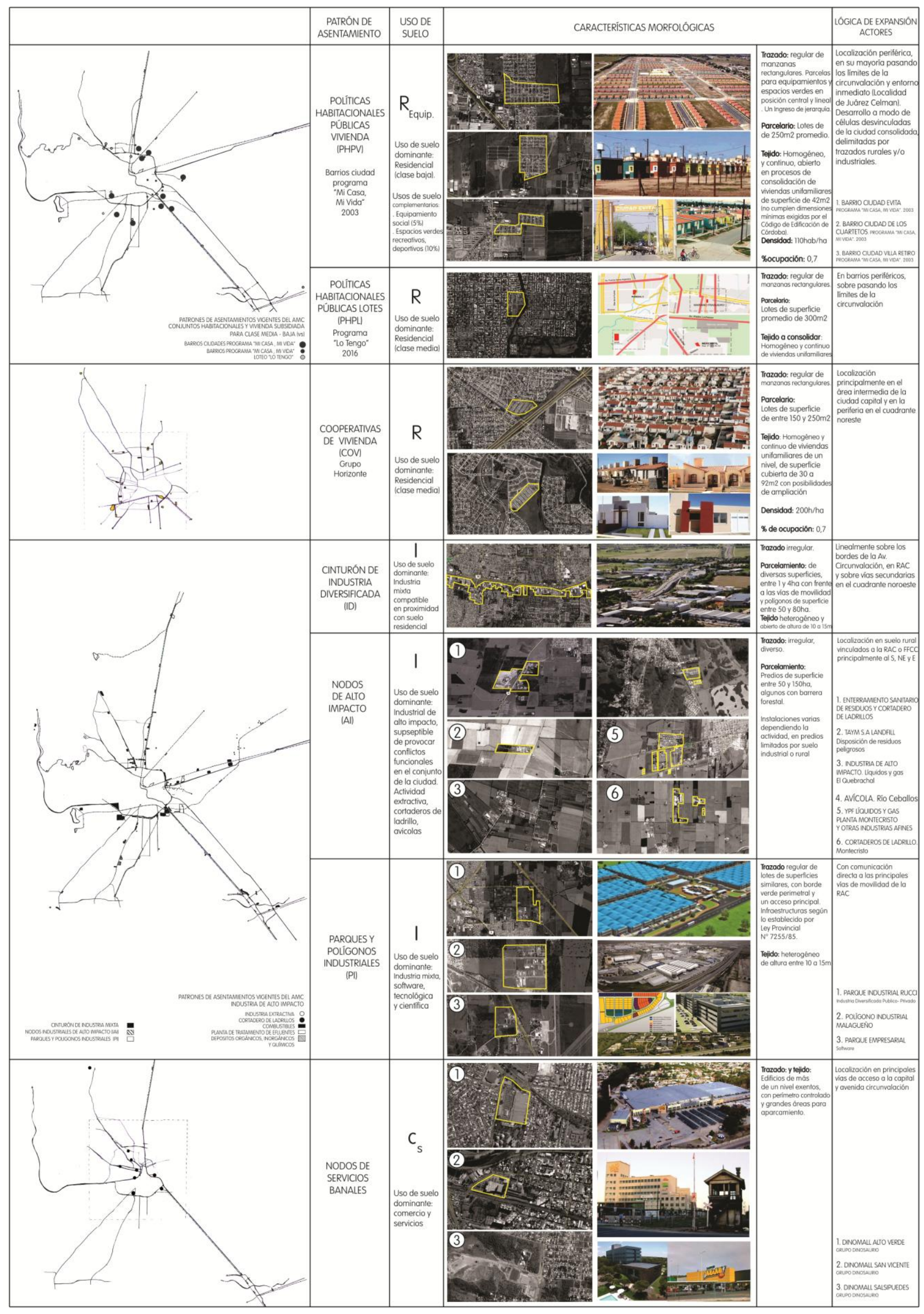



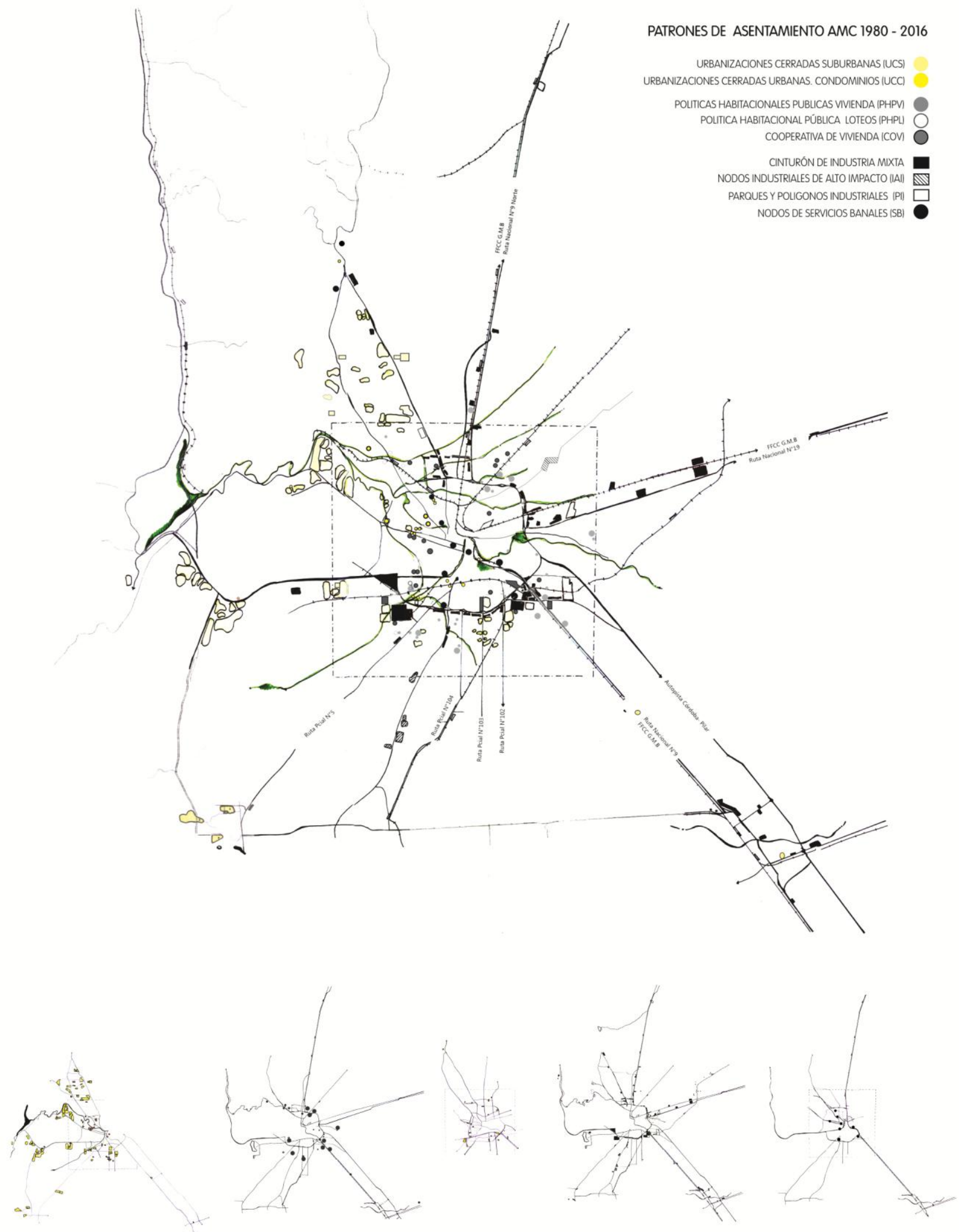

URBANIZACIONES CERRADAS (UCS - UCC) 

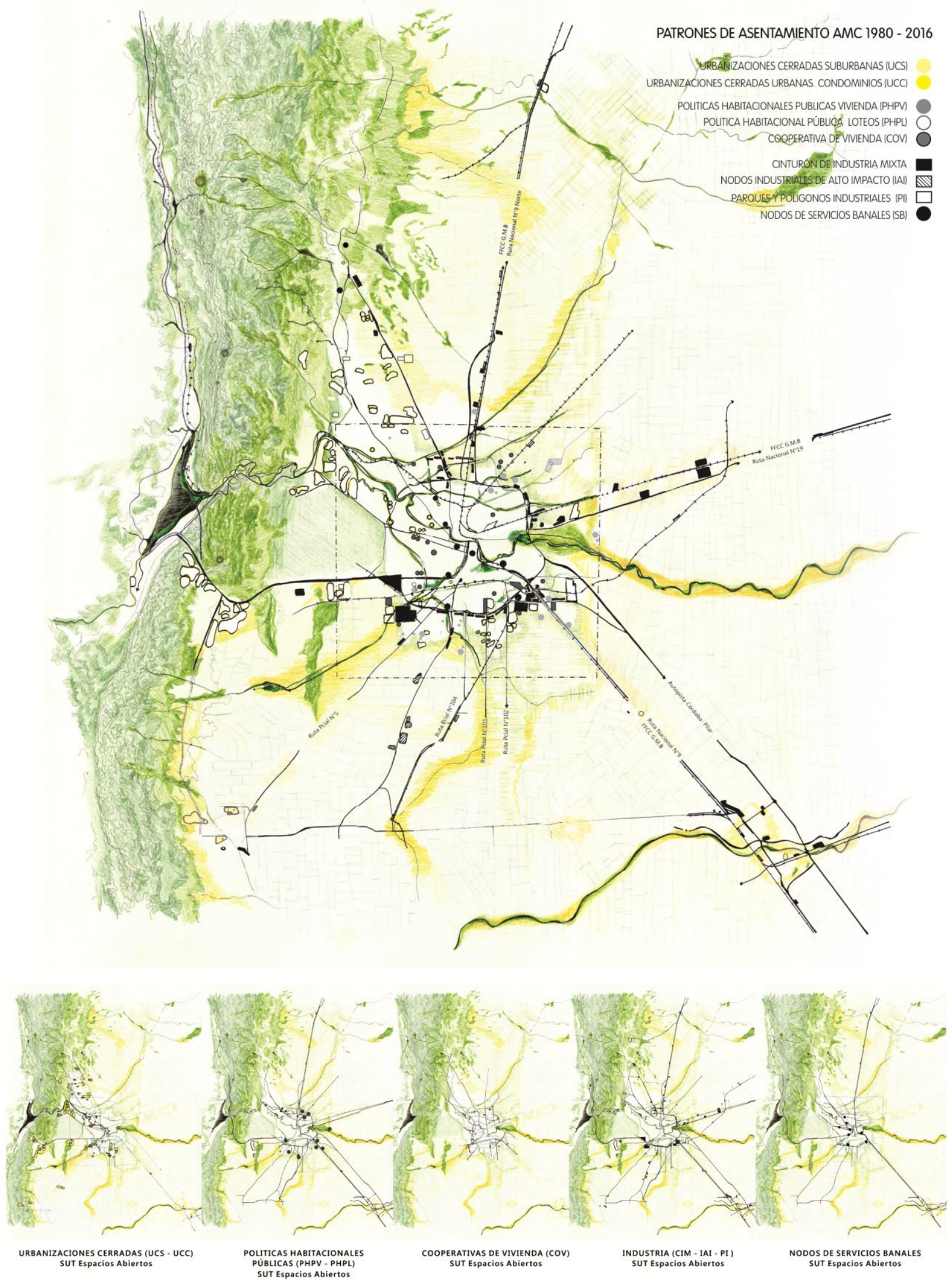


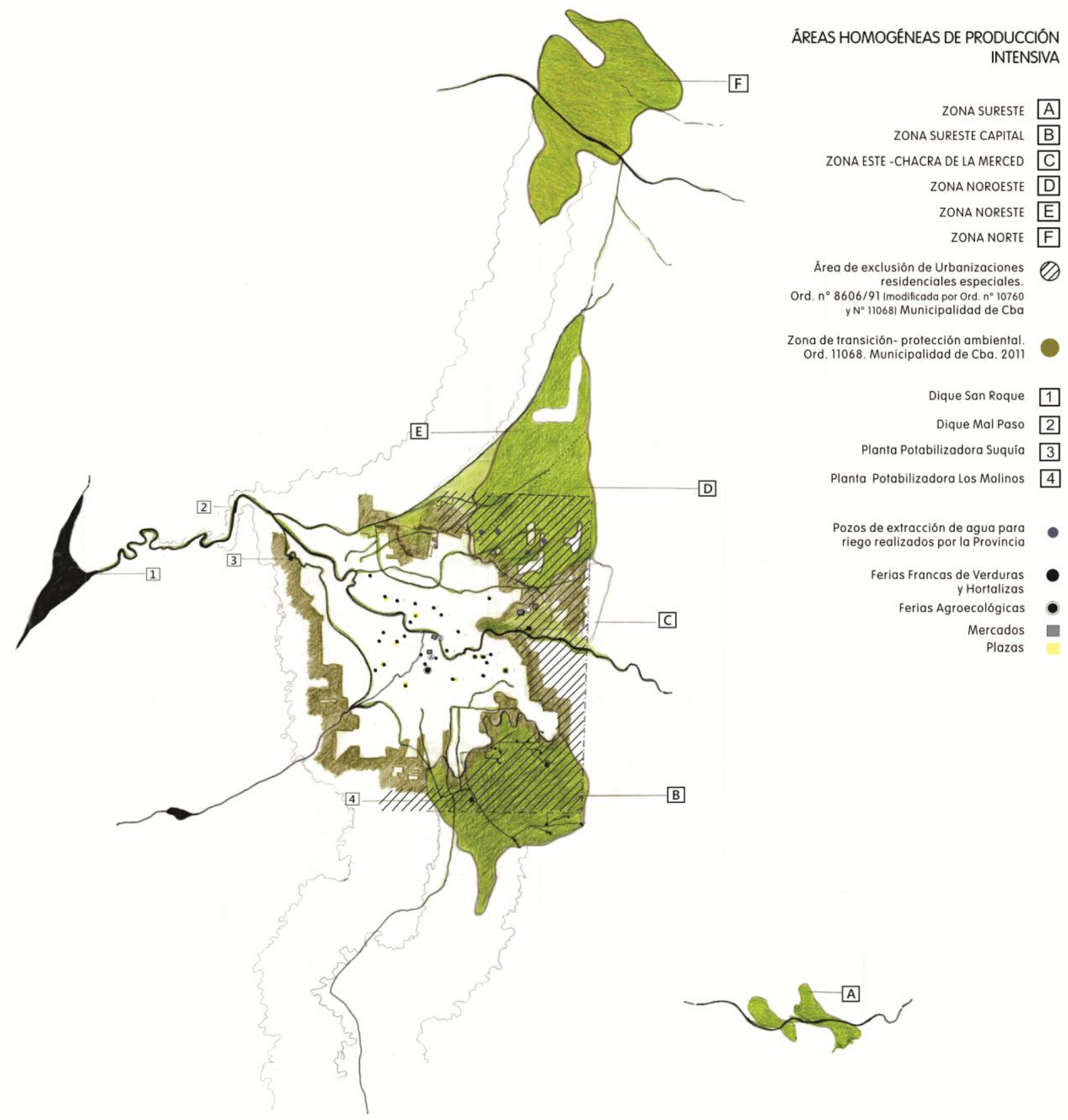

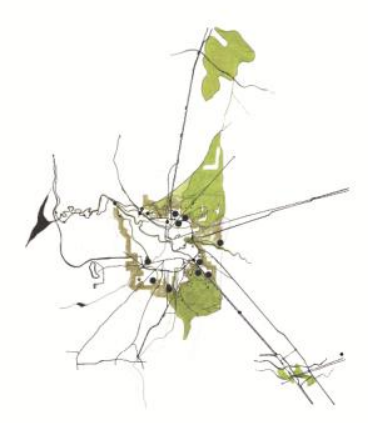

POLITICAS HABITACIONALES AREAS DE PRODUCCION INTENSIVA

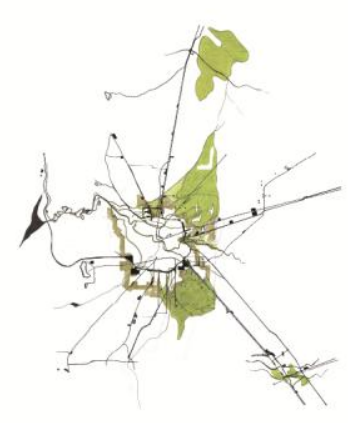
INDUSTRIA (CIM - IAI - PI)
AREAS DE PRODUCCIÓN INTENSIVA

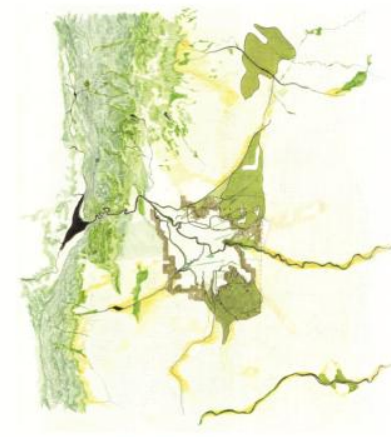

AREAS DE PRODUCCIÓN INTENSIVA SUT Espacios Abiertos

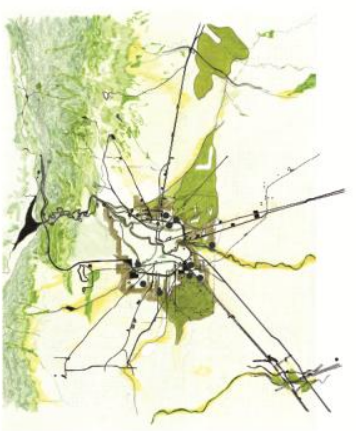

AREAS DE PRODUCCIÓN INTENSIVA SUT Espacios Abiertos
Patrones de asentamiento en relación 

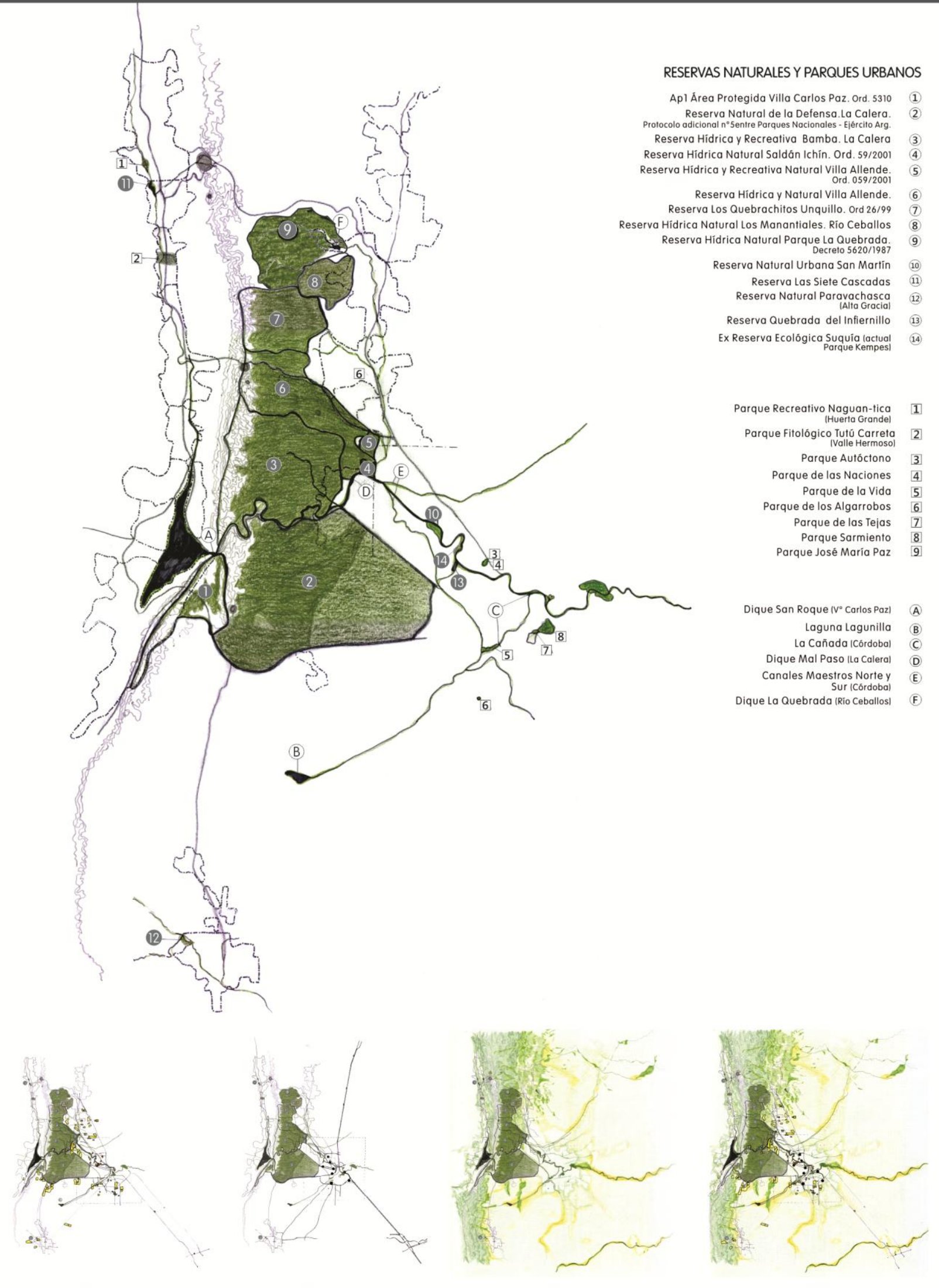

URBANIZACIONES CERRADAS (UCS - UCC)

NODOS DE SERVICIOS BANALES Corredor de las Sierras Chicas SUT Espacios Abiertos
Corredor de las Sierras Chicas

CORREDOR DE LAS SIERRAS CHICAS

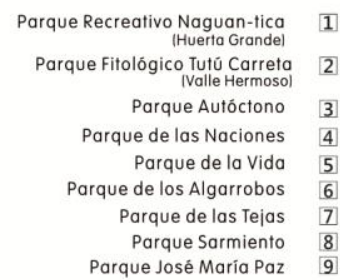

Dique San Roque (V Carlos Paz) (A) Laguna Lagunilla B La Cañada ICórdobal C Dique Mal Paso lla Caleral (D) Canales Maestros Norte y E Dique La Quebrada (Rio Ceballos) F 


\section{BIBLIOGRAFIA}

SABATÉ, Joaquín. "De la cartografía urbana al proyecto territorial", en Café de las Ciudades, Buenos Aires, № 93, 2010.

CORBOZ, André. Le Territoire comme palimpseste et autres essais, Les Éditions de l'imprimeur, Besançon, Francia, 2001.

FOLCH, R. coord. El territorio como sistema. Conceptos y herramientas de ordenación. Barcelona: Diputación, 2003.

SOLÁ-MORALES, Manuel de. "Las formas del crecimiento urbano", Ediciones UPC, Barcelona, 1997.

BORSDORF, Axel. "Cómo modelar el desarrollo y la dinámica de la ciudad latinoamericana", en EURE, Santiago, v.29 n.86, 2003.

CICOLELLA, Pablo, MIGNAQUI, Iliana. "Capitalismo global y transformaciones metropolitanas: enfoques e instrumentos para repensar el desarrollo urbano", en POGGIESE, H., COHEN EGLER, T., comp. Otro desarrollo urbano. Ciudad incluyente, justicia social y gestión democrática. Buenos Aires: CLACSO. 2009.

BORJA, Jordi. "Manifiesto de Quito. Foro Hábitat 3 Alternativo", en jordiborja.cat, 2016.

FONT, Antonio (2005). "Problemas urbanos y paradigmas disciplinares en los territorios de la urbanística actual". En FONT, A et al, edits. Los territorios del urbanista: UPC

DÍAZ TERRENO, Fernando. "Propuesta pedagógica Cátedra Urbanismo 2B, FAUD, UNC", Córdoba. 2014.

GOYTIA, Noemi, FOGLIA, María Elena. "Procesos de Modernización de Córdoba". Publicaciones de la Facultad de Arquitectura, Urbanismo y Diseño de la UNC, 1990.

BUTHET, Carlos, BAIMA, Marta, MALDNADO, Martín. "La población de las 'villas de emergencia' de Córdoba. Origen, situación socio- económica y organizativa y expectativas respecto al hábitat".

MARENGO, Cecilia. "La Periferia de Córdoba. Cuestiones sobre el Hábitat Urbano". Publicaciones de la Facultad de Arquitectura, Urbanismo y Diseño de la UNC, 2006.

MARENGO, Cecilia; MONAYAR, Virginia. "Crecimiento Urbano y e informalidad residencial. El caso de Nuestro Hogar III en la periferia de Córdoba, Argentina", en Cuaderno Urbano, versión on-line ISNN vol. 13 no. 13, 2012.

GIOBELLINA, Beatriz. "Agricultura urbana y periurbana, patrimonio agrario para la sustentabilidad de las ciudades. Lecciones aprendidas: del periurbano de Valencia al periurbano de Córdoba”. Articulo Seminario de Innovación Territorial. Lecciones aprendidas.

CRISAFULLI, Luciano, BARALLA, Gabriel. "Parques Industriales en la Provincia de Córdoba". eralpyme.org, 2011. Lineamientos del plan estratégico urbano territorial de la región metropolitana de Córdoba. Córdoba, IPLAM, Gobierno de la Provincia de Córdoba, 2012. Bases para un Plan Director de la Ciudad de Córdoba. Lineamientos y Estrategia general para el reordenamiento del territorio. Secretaría de Desarrollo Urbano de la Municipalidad de Córdoba y Facultad de Arquitectura, Urbanismo y Diseño, 2008.

Córdoba una Ciudad en Cifras. Guía Estadística de la Ciudad de Córdoba. Secretaria de Planeamiento y Desarrollo Estratégico y Dirección de Estadísticas y Censos. Municipalidad de Córdoba, 2012. Córdoba una Ciudad en Cifras. Guía Estadística de la Ciudad de Córdoba. Secretaria de Planeamiento y Desarrollo Estratégico y Dirección de Estadísticas y Censos. Municipalidad de Córdoba, 2014.

Área de Exclusión de Urbanizaciones residenciales espaciales Ordenanza №8606/91 (modificada por ord. $\mathrm{N}^{\circ} 10760$ y Ord. N¹1068). Municipalidad de Córdoba, Argentina.

Zona de Transición - Protección ambiental Ord. № 11068. Modificatoria de Ord. № 10760. Municipalidad de Córdoba, Argentina.

Ley Provincial de Bosques № 9814/2010. Gobierno de la Provincia de Córdoba, Argentina.

Ordenanza de Uso de Suelo № 8133/85. Municipalidad de Córdoba, Argentina.

Ordenanza de Uso de Suelo № 8256/852. Municipalidad de Córdoba, Argentina.

Fuentes digitales:

https://wikimapia.org

https://www.indec.gov.ar

https://www.cordoba.gob.ar

https://www.cba.gov.ar

https://www.cordoba.turismo.gov.ar

https://iralpyme.org

https://www.lavozdelinterior.com.ar (22/02/2015)

https://www.Agenda4p.com (7/08/16) 
https://www.latinta.com.ar (26/10/2016)

https://www.latinta.com.ar (16/12/2016)

https://www.cba25n.com (01/04/15)

https://www.cba25n.com (17/04/05)

https://infonegocios.com (09/08/206)

https://impulsonegocios.com (09/08/2016)

https://comercioyjusticia.com (02/11/2012) 